\title{
Mitochondrial stress management: a dynamic journey
}

\author{
Miriam Valera-Alberni ${ }^{1,2}$ and Carles Canto ${ }^{1,2} *$ \\ ${ }^{1}$ Nestlé Institute of Health Sciences (NIHS), EPFL Innovation Park, 1015 Lausanne. \\ ${ }^{2}$ School of Life Sciences, EPFL, 1015 Lausanne. \\ * Corresponding Author: \\ Carles Cantó, Nestlé Institute of Health Sciences S.A., EPFL Innovation Park, Building G, Lausanne, CH-1015, Phone: +41 (0) \\ 216326116; Switzerland; E-mail: carlos.cantoalvarez@rd.nestle.com
}

ABSTRACT Mitochondria undergo continuous challenges in the course of their life, from their generation to their degradation. These challenges include the management of reactive oxygen species, the proper assembly of mitochondrial respiratory complexes and the need to balance potential mutations in the mitochondrial DNA. The detection of damage and the ability to keep it under control is critical to fine-tune mitochondrial function to the organismal energy needs. In this review, we will analyze the multiple mechanisms that safeguard mitochondrial function in light of in crescendo damage. This sequence of events will include initial defense against excessive reactive oxygen species production, compensation mechanisms by the unfolded protein response $\left(U P R^{\mathrm{mt}}\right.$ ), mitochondrial dynamics and elimination by mitophagy. doi: $10.15698 /$ cst2018.10.158

Received originally: 08.06.2018

in revised form: 12.09 .2018 ,

Accepted 19.09.2018,

Published 08.10.2018.

Keywords: mitochondria, mitochondrial dynamics, oxidative stress, unfolded protein response, mitophagy, mitochondrial biogenesis.

\section{Abbreviations:}

$\alpha-K G-\alpha$-ketoglutarate,

$A \beta$ - amyloid $\beta$ peptide,

$A M P K$ - AMP-activated protein kinase,

$A P$ - autophagosome,

CAT - catalase,

CHOP - C/EBP homologous protein,

CLPP - ATP-dependent caseinolytic protease proteolytic subunit,

COX - cytochrome Coxidase

$E R$ - endoplasmic reticulum,

$G P x$ - glutathione peroxidases,

IMM - inner mitochondrial membrane,

IMS - intermembrane space,

ISR - integrated stress response,

$M D P$ - mitochondrial derived peptide,

MSR-mitochondrial stress response,

mtDNA - mitochondria DNA,

OMM - outer mitochondrial membrane,

OXPHOS-oxidative phosphorylation,

PERK - protein kinase RNA-like ER kinase,

PGC-1 $\alpha$-Peroxisome Proliferator Activator

Receptor Gamma Coactivator 1a,

PINK1 - PTEN-induced putative kinase 1,

ROS - reactive oxygen species,

$S O D$ - superoxide dismutase,

TCA - tricarboxylic acid cycle,

$\operatorname{TrRx}$ - Thioredoxin reductases,

UPR - unfolded protein response,

$\Delta \Psi_{m}$ - mitochondrial membrane potential. 


\section{INTRODUCTION}

The eukaryote cell is an exceptionally complex organization of macromolecules. While initial crucial steps in the origin of eukaryote life might include the development of flexible cell surface, complex cytoskeletal organizations and heavily specialized cell compartmentalization, the ability of the cell to communicate with the external milieu has been vital for the efflorescence of specialized tissues and multicellular organisms.

The origins of mitochondria probably find their place in the engulfment and symbiotic establishment of a proteobacteria into the protoeukaryotic cell. Mitochondria act as the cellular powerhouses and play a central role in bioenergetics and metabolism of amino acids and lipids, since they host fatty acid $\beta$-oxidation, the Kreb's cycle (also known as the tricarboxylic acid (TCA) cycle) and oxidative phosphorylation (OXPHOS) [1]. However, bioenergetics is far from being the only fundamental role of mitochondria in global cell biology. Mitochondria also regulate calcium stores, lipogenesis and the production of steroid hormones [1]. They can even determine cell fate via apoptotic cues. Mitochondria also play a crucial function in cellular redox homeostasis, as leakage of electrons through the electron transport chain generates reactive oxygen species (ROS) which, in controlled amounts, constitute valuable secondary messengers [2].

Nevertheless, mitochondrial physiology engages into a number of significant challenges. One of them, intrinsic to its respiratory function, is the management of $\mathrm{O}_{2}$ and ROS. An imbalance between ROS generation and the organismal/cellular system's ability for clearance, promotes oxidative damage to lipids, nucleic acids and proteins [2]. Similarly, the mitochondrial matrix undergo massive fluxes of metabolites, such as short-chain acyl-CoAs, that can covalently bind to proteins and modify their function [3]. Finally, one cannot forget that, despite mitochondria are physically delimited by two membranes, most of their proteins need to be imported and assembled in the mitochondrial compartment with exquisite stoichiometry. Therefore, there has been an evolutive pressure favoring the existence of coordinated cellular responses to mitochondrial stress and damage. This is a complex task, as the nature and extent of the damage can be largely variable. Further, hundreds of individual mitochondria can populate a cell, so there should be ways to differentiate between local damage in an individual mitochondrion from widespread mitochondrial toxicity. In the sections to come, we will explore how mitochondria respond to different and increasing types of damage, orchestrating either reparative or recycling strategies.

\section{MITOCHONDRIA: THE COMMUNICATING ORGANELLE}

Mitochondria have historically been viewed as relatively passive generators of the ATP that is necessary to thermodynamically drive many cellular biochemical reactions. However, mitochondria have also developed mechanisms to communicate with the rest of the cell, probably to ensure that cells do not commit to a biological event that mitochondria cannot metabolically sustain (see review [4]). An early example for this concept was built in the late 1990s, upon the discovery that release of cytochrome $C$ from the mitochondrial intermembrane space to the cytosol induced apoptosis [5].

Mitochondria communicate with the cellular environment through multiple molecular entities (Figure 1). The biochemical nature of these molecules is very broad and includes mitochondrial DNA (mtDNA) fragments, mitochondrial lipids (e.g.: cardiolipin), metabolites and small peptides (see [6] for extended review). These communication mechanisms are not necessarily linked to mitochondrial dysfunction, but used as information on multiple cues, such as nutrient fluxes or redox states. Mitochondrial derived peptides (MDPs), for example, are signaling peptides encoded by short open reading frames in the mitochondrial genome [7]. MDPs contribute to a plethora of cellular pathways, by promoting cellular viability and reducing apoptosis [7-9]. Humanin, the first discovered MDP, is a 24 amino acid peptide encoded in the $16 \mathrm{~S}$ ribosomal RNA in the mtDNA [9], with reported neuroprotective function against amyloid $\beta$-peptide $(A \beta)$ toxicity and Alzheimer's disease (AD) pathology [10]. Treatment of rat models with humanin inhibited the neurotoxic effect of $A \beta$ aggregates and restored memory deficits of $A \beta$-induced tau hyperphosphorylation [10]. In mammalian cells, humanin can bind to the apoptosis-inducing protein Bax. In response to stress, Bax can translocate from the cytosol to the mitochondrial outer membrane, where it inserts and promotes cell death through the release of cytochrome $C$ and other apoptogenic proteins. The interaction with humanin suppressed Bax translocation to mitochondria, preventing apoptosis [11]. Humanin can also be released to the blood flow [12]. In this line, the interaction of humanin and circulating IGFBP-3 (IGF binding protein 3) inhibited IGFBP-3induced cell death on human glioblastoma cells [13]. Overall, this evidence demonstrates that humanin cytoprotective function is mediated by its interaction with intracellular and extracellular components $[11,13]$. Of note, humanin's protective role is not only restricted to mitochondria, but has also been shown to protect the endoplasmic reticulum (ER) against ER stress-induced apoptosis [14], mediated by the restoration of mitochondrial glutathione depleted by ER stress.

In silico analyses revealed six additional peptides encoded in the same region as humanin, named small humanin-like peptides (SHLPs) with similar function to humanin and whose levels decreased with age [9]. SHLP2 specifically targets misfolded amyloid seeds to inhibit islet amyloid polypeptide (IAPP) misfolding, a critical pathogenic step in type 2 diabetes mellitus [7]. In parallel to humanin and SHLPS, MOTS-c (Mitochondrial Open Reading Frame of the $12 \mathrm{~S}$ rRNA-c) is a 16 amino acid peptide encoded within the mitochondrial $12 \mathrm{~S}$ rRNA that promotes metabolic homeostasis and reduces obesity and insulin resistance in mice [8]. HEK293 cells stably expressing MOTS-c exhibited inhibition of the folate-methionine cycle, blockade of de novo purine biosynthesis, leading to the accumulation of one of its intermediates, AICAR, and the activation of the 


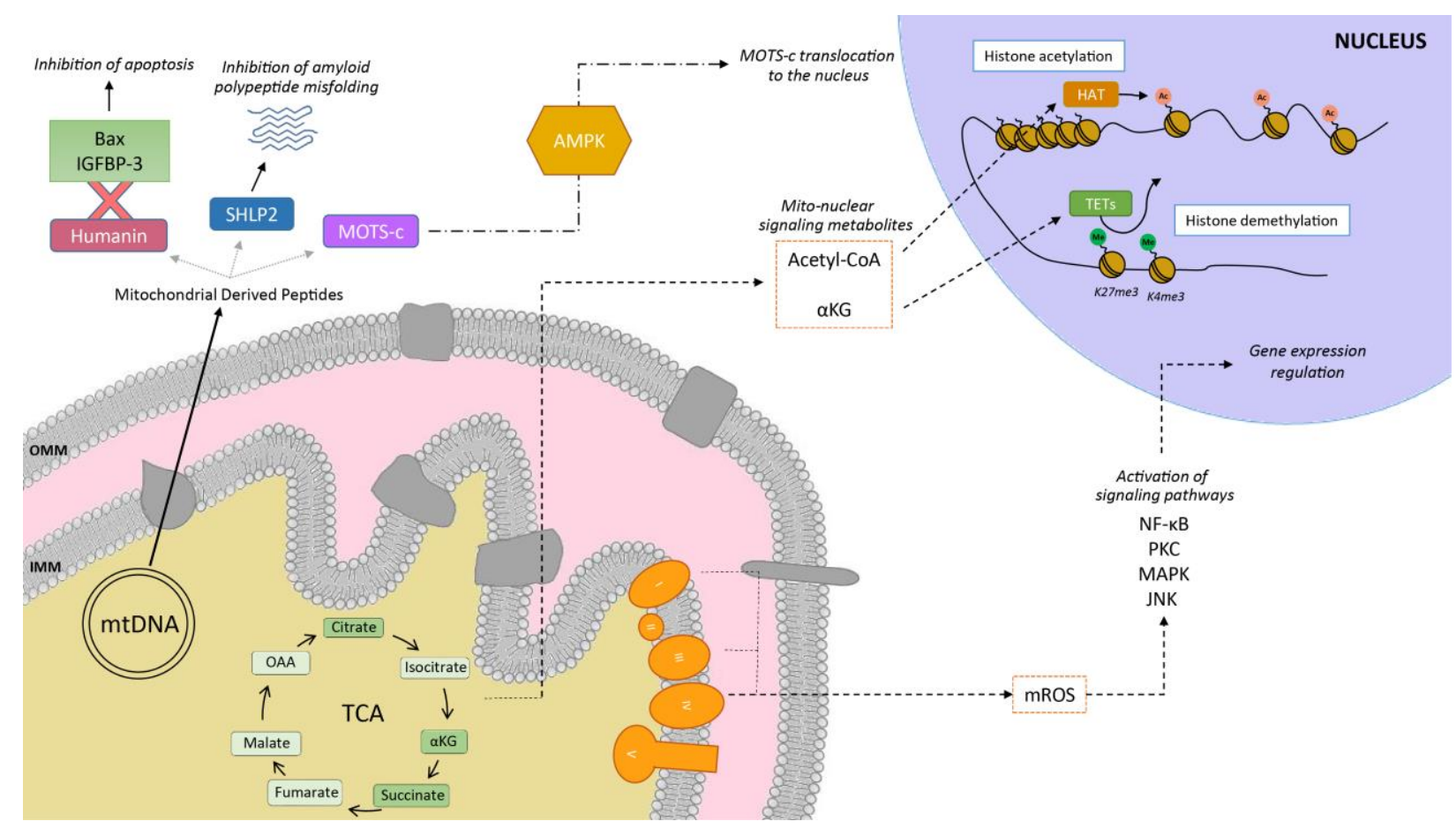

FIGURE 1: Mitochondria as communicating organelles. The figure illustrates some examples of how mitochondria communicate with the nucleus. This includes mitochondrial derived peptides (MDPs), metabolites or mitochondrial reactive oxygen species (mROS). Humanin's cytoprotective function is mediated by its binding to Bax and IGFBP-3, preventing cellular apoptosis. Other MDPs include small humaninlike peptides (SHLPs), such as SHLP2, which specifically targets misfolded amyloid seeds to inhibit amyloid polypeptide misfolding. MOTS-c (Mitochondrial Open Reading Frame of the 12S rRNA-c) are MDPs that promote metabolic homeostasis and prevent metabolic stress by its translocation to the nucleus, provided by the metabolic regulator AMPK. Mitochondria are also one of the main sources for acetyl-CoA, which is required by the histone acetyltransferases (HATs) for histone acetylation. Acetylation of histones results in a transcriptionally active chromatin configuration that promotes gene expression. Further, the tricarboxylic acid cycle (TCA) metabolite $\alpha$-ketoglutarate $(\alpha K G)$ is the substrate of the histone demethylase ten-eleven translocation enzymes (TETs) which demethylate the K27me3 and K4me3 histone 3 tails. Finally, mROS are generated primarily by the complexes I and III of the electron transport chain, and are then able to diffuse into the cytoplasm to activate various signaling pathways, and regulate the expression of specific genes.

metabolic regulator AMPK [8]. Interestingly, MOTS-c was recently proved to translocate to the nucleus and regulate nuclear gene expression in an AMPK-dependent manner, promoting stress resistance against glucose restriction [15]. Further, MOTS-c treated mice showed significantly enhanced glucose clearance indicative of improved skeletal muscle insulin sensitivity [8], which points out the muscle as the main target of MOTS-c. MOTS-c treatment in mice also prevented age-dependent and high fat diet induced insulin resistance and obesity [8]. These observations suggest that mitochondria actively regulate cellular cues by releasing peptides encoded within their own genome.

Metabolites released from the mitochondria to the nucleus also act as retrograde signaling systems, and many of them constitute substrates for chromatin-modifying enzymes (Figure 1). This allows coupling chromatindependent gene regulation with the metabolic state of the cell [16]. For instance, acetyl-CoA is an intermediary metabolite that participates in the mitochondrial TCA cycle by interacting with oxaloacetate to produce citrate, but also has a signaling role by the acetylation of proteins. It is generated from acetate, citrate and pyruvate, and also by the breakdown of both carbohydrates (glycolysis) and lipids ( $\beta$ - oxidation). Acetyl-CoA production is essential for the activity of histone acetyltransferases (HATs), enzymes responsible of acetylating histone lysine residues. Acetylation of histones decreases the interaction between histones and DNA, giving rise to a transcriptionally active chromatin configuration that promotes gene expression. Initial observations on the interplay between the metabolic state and histone acetylation response to growth were made in yeast. In yeast, one pathway to produce acetyl-CoA relies on acetyl-CoA synthetases Acs1p and Acs $2 p$, which catalyze the ligation of acetate and CoA. Acs $2 p$ yeast mutants exhibited global histone deacetylation, correlated to broad decreases in gene expression and growth defects [17]. In a complementary study, elevated glucose levels in yeast resulted in fueled production of acetyl-CoA, promoting the activity of the transcriptional coactivator complex SAGA (Spt-AdaGcn5-Acetyltransferase) [18], to acetylate histones specifically at the genes responsible of cell growth [19]. Hence, a yeast cell coordinates its growth with the production of acetyl-CoA, which is indicative of its metabolic and nutritional state [19]. These observations of metabolic cues directly altering histone acetylation have also been extended to mammalian cells. Glucose is the major source for 
mammalian cells and it can be used by ATP-citrate lyase $(A C L)$, the enzyme that converts glucose-derived citrate into acetyl-CoA. RNA-induced silencing of ACL led to the decrease in global histone acetylation in response to growth factor stimulation, while it also resulted in impaired differentiation in adipocytes [20]. ACSS2 (the mammalian equivalent of $A c s 2 p$ ) is highly expressed in the mouse hippocampus, the area in charge of memory consolidation. Attenuated ACC2 expression in adult mice showed impaired long-term spatial memory, correlated to a defective upregulation of immediate-early memory genes [21]. Acetyl-CoA generation via ACSS2 establishes, thus, a connection between cellular metabolism, epigenetic modifications and, in the above case, neuronal plasticity [21]. Similarly, another key chromatin modification that is strongly interconnected with metabolism is methylation. In this sense, some demethylases, such as the ten-eleven translocation (TET) methylcytosine hydroxylases require $\alpha$-ketoglutarate $(\alpha-K G)$ as an essential co-substrate [22]. $\alpha$-KG is a TCA metabolite that functions as a co-substrate for 2-oxoglutaratedependent dioxygenases, which catalyze hydroxylation reactions on various types of substrates. High levels of $\alpha$ KG promote TET-dependent DNA demethylation of $\mathrm{K} 27 \mathrm{me} 3$ and $\mathrm{K} 4 \mathrm{me} 3$ histone 3 tails [23], again pointing towards an intimate link between metabolism and DNA demethylation.

Mitochondria are also an important source for ROS. ROS molecules have long been known as being damaging and pernicious agents to the cell, resulting in oxidative stress (see section 2, below). However, ROS play a critical role as signaling molecules to maintain physiological functions. In this regard, superoxide anions and hydrogen peroxide were probed to activate signaling pathways controlled by tyrosine phosphorylation such as NF-KB, PKC, MAPK or JNK [24, 25] (Figure 1). ROS react with the redoxsensitive cysteine residues of tyrosine phosphatases leading to their transient inactivation, which favors unopposed kinase activity $[26,27]$. Nowadays, ROS have been demonstrated to contribute in many physiological events including adaptation to hypoxia and physical activity, regulation of autophagy, immunity, differentiation and longevity (detailed in [26]). For instance, ROS formation and low-level stress due to reduced glucose availability (calorie restriction) was proposed to culminate in stress resistance [28] and was shown to extend life span in C. elegans [29]. This was one of the founding observations for the concept of mitochondrial hormesis or mitohormesis, in which mitochondrial stresses rapidly activate cytosolic signaling pathways that ultimately alter nuclear gene expression aimed to strengthen the defense towards the initial stress [30, 31] In this sense, mitochondrial ROS production can be observed as a mitohormetic signal. Hence, there is no linearity between ROS production and cellular toxicity. Nevertheless, given that excessive ROS production can be damaging to the cell, mitochondrial ROS levels are tightly regulated by multiple systems in order to ensure their ability to participate in physiological cell signaling while preserving cell homeostasis, as described in our next chapter.

\section{OXIDATIVE STRESS}

The integration of an $\alpha$-proteobacterium within an ancient host cell around 1.45 billion years ago was key for the survival and replication of the host in an environment with increasing oxygen $\left(\mathrm{O}_{2}\right)$ levels. This proteobactium helped in the removal of the $\mathrm{O}_{2}$ that was being diffused inside the host cell from the environment $[32,33]$. The coupling of $\mathrm{O}_{2}$ consumption to ATP synthesis allowed the sustainability of eukaryotic cellular bioenergetics as we know them today. In addition, aerobic metabolism spurred the generation of new metabolites such as steroids, alkaloids and isoflavonoids [34, 35].

$\mathrm{O}_{2}$ is nowadays not only linked to ATP synthesis through the mitochondrial electron transport chain (ETC), but also to the remodeling of protein structure and function, for example, via post-translational modifications [36]. Nevertheless, some of the metabolic products of the oxidative phosphorylation remain a threat to cell survival when their production and removal are not properly balanced. The ETC is one of the main producers of ROS, a wide name for a constellation of oxygen anion forms that include superoxide $\left(\mathrm{O}_{2}{ }^{-}\right)$, hydrogen peroxide $\left(\mathrm{H}_{2} \mathrm{O}_{2}\right)$ and the hydroxyl free radical $(\mathrm{OH}-) . \mathrm{O}_{2}^{-}$causes the formation of other reactive species: it can directly produce $\mathrm{OH}$ - or indirectly through the dismutation of $\mathrm{H}_{2} \mathrm{O}_{2} \cdot \mathrm{H}_{2} \mathrm{O}_{2}$ has low reactivity, but high penetrability in cell membranes and when it accumulates, it is highly toxic to cells $[37,38]$. Also, $\mathrm{H}_{2} \mathrm{O}_{2}$ can be converted to $\mathrm{OH}$ - in the presence of $\mathrm{Fe}^{2+}$ [39]. $\mathrm{OH}$ - is the most reactive and dangerous form of oxygen, as it can react with all biological macromolecules [38, 40].

Excessive ROS production or an ineffective antioxidant response results in oxidative stress [41], promoting mitochondrial dysfunction and affecting cell viability by damaging nucleic acids, proteins and lipids. In this regard, ROS accumulation can lead to DNA base modification, DNA strand breaks, inter- and intra-strand crosslinks and DNAprotein crosslink that ultimately affect genomic structure and stability [42]. Similarly, changes in protein structure and function can arise from the oxidation of cysteine residues, which are intrinsically vulnerable to oxidative stress because of the highly reactive nucleophilic thiol moiety [43]. Lipid membranes promote the formation of lipid radicals when exposed to free radicals, leading to the most devastating effect of oxidative stress, which is lipid peroxidation and altered membrane permeability and stability, ultimately compromising cellular compartmentalization and overall function [44]. Not surprisingly, the macromolecular damage caused by increased oxidative stress has been linked to multiple pathologies such as atherosclerosis, diabetes, cancer and chronic inflammatory processes, as well as age-related physiological deterioration [37, 45-48].

Eukaryotic cells harbor complex antioxidant strategies to protect against an uncontrolled increase in free radicals. This includes both enzymatic and non-enzymatic mechanisms (i.e. vitamins). The enzymatic response is primarily mediated by superoxide dismutases (SOD), catalases, thioredoxin reductases or glutathione peroxidases [49]. SOD enzymes catalyze the conversion of $\mathrm{O}_{2}^{-}$to $\mathrm{H}_{2} \mathrm{O}_{2}$ and $\mathrm{O}_{2}$, and 
they are considered as one of the most powerful antioxidant agents in cells (Figure 2) [38]. Various forms of SOD enzymes exist, that differ in their cellular localization and the metal cofactor used for their catalytic activity [50]. SOD1 is a soluble $\mathrm{Cu} / \mathrm{Zn}$ enzyme that is mainly present in the cytosol, although a small percentage (approx. $3 \%$ ) also exists in the intermembrane space of mitochondria [51]. Upon increased levels of $\mathrm{H}_{2} \mathrm{O}_{2}$, SOD1 can translocate to the nucleus, where it binds to DNA promoters and favors the expression of oxidative resistance and repair genes [52]. MnSOD (encoded by the SOD2 gene) has been described to be located exclusively in mitochondria [53], being the primary defense against mitochondrial oxidative stress. In this sense, SOD2 deletion has been linked to defective pancreatic $\beta$-cell secretory capacity [54], as well as cancer progression in a tissue-specific manner $[55,56]$. SOD3 is a secretory extracellular $\mathrm{Cu} / \mathrm{ZnSOD}$ which is expressed highly in selected tissues, including the gastrointestinal tract, blood vessels, lung or kidneys [57]. Once released, SOD3 binds to the surface of endothelial cells rich in sulfated polysaccharides such as heparin and heparan sulfate, and this helps endothelial cell function by protecting from oxidantmediated damage, inflammation, and interstitial fibrosis in lung $[58,59]$.

Catalases (CAT) can break down $\mathrm{H}_{2} \mathrm{O}_{2}$ into water and molecular oxygen by utilizing iron or manganese as a cofactor, thereby completing the detoxification initiated by SOD [60]. CAT enzymes are predominantly found in peroxisomes but absent in mitochondria of mammalian cells [61, 62]. In this case, the conversion of $\mathrm{H}_{2} \mathrm{O}_{2}$ to $\mathrm{H}_{2} \mathrm{O}$ and $\mathrm{O}_{2}$ is carried out by another type of enzymes known as glutathione peroxidases (GPx), which use a selenium intermediate and glutathione as substrates [63]. GPx play also a crucial role breaking lipid peroxides to their alcohols, which protects cells from oxidative stress $[64,65]$. The expression of individual GPx is tissue-specific and has been classified into eight groups $[66,67]$. For example, GPx1 is the most abundant form and is present in all cells; GPx2 is exclusively expressed in the gastrointestinal track, providing a barrier against hydroperoxides produced in the diet, while plasma GPx (GPx3) is directed to extracellular compartments and is mainly expressed in tissues in contact with body fluids (i.e, kidney) (for a detailed review, see [68]). While both GPx and catalases use $\mathrm{H}_{2} \mathrm{O}_{2}$, it has been proposed that the glutathione redox cycle is a source of protection against mild oxidative stress as compared to CAT, which protect against severe oxidative stress [69].

Thioredoxin reductases (TrxRs) are enzymes characterized by the redox activity of its flavin adenine nucleotide (FAD) group, which helps reducing thioredoxins (Trxs) by the oxidation of NADPH to NADP ${ }^{+}$[70]. Trx, once reduced, supplies electrons to enzymes such as peroxiredoxins or Trx peroxidases, which regulate the conversion of $\mathrm{H}_{2} \mathrm{O}_{2}$ into water [71-73]. Mammalian cells contain two TrxRs, the cytosolic TrxR1 and the mitochondrial TrxR2. Apart from protection against oxidant stress, some of the biological functions of TrxRs include cell growth, promoting transcription factor activity, ascorbate recycling or tumor resistance [74]. Both TrxRs and GPx have been demonstrated to also protect against nitrosative stress, concretely nitrosothiols and peroxynitrite [75].

The expression of ROS metabolizing enzymes can be directly controlled by oxidative stress. Primary responses to ROS are modulated by the cooperation of the NF-KB, AP1 and MAPK pathways. When these responses are not sufficient to counteract the increase in ROS, the NRF2/KEAP cascade is activated to induce antioxidant defenses and minimize oxidative damage [49]. The mitochondrial complex $\mathrm{I}$, although being one of the main generators of $\mathrm{O}_{2}^{-}$, also contributes to the antioxidant response by inducing

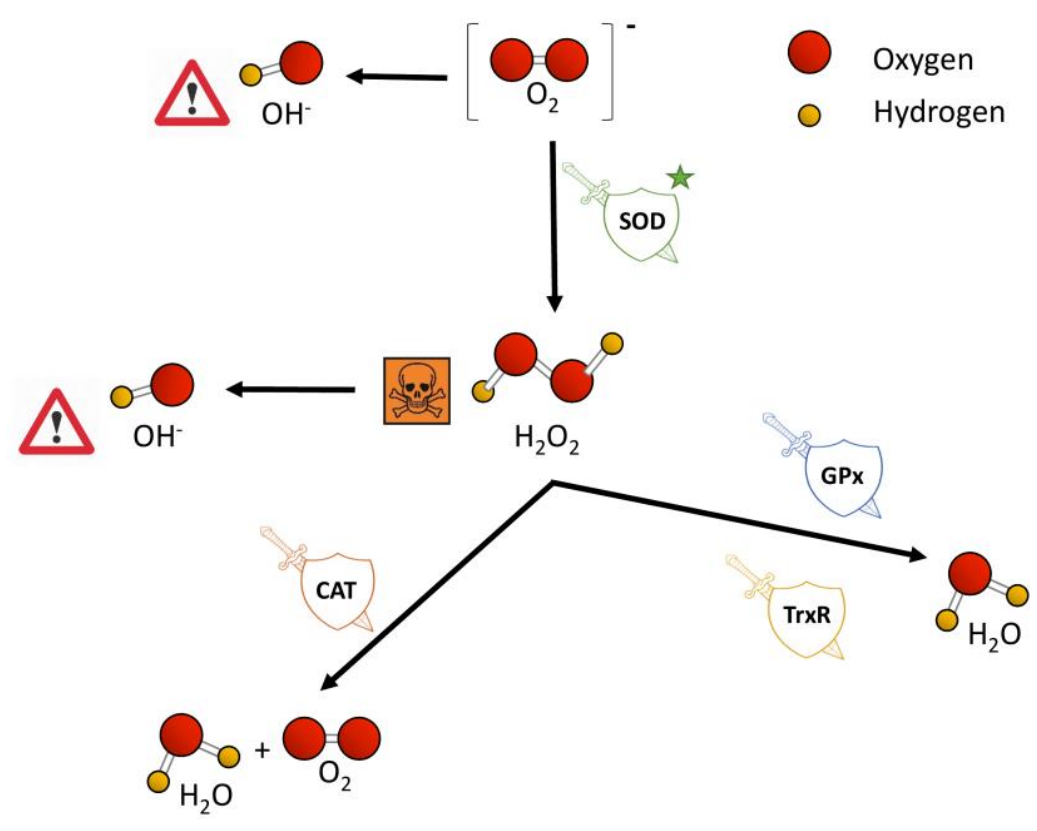

FIGURE 2: Toxic ROS generation and enzymatic antioxidant defenses. Cells encompass a group of enzymes which help counterbalancing the potential detrimental effects of ROS production upon toxic levels. $\mathrm{O}_{2}$, generated as a by-product from the electron transport chain in mitochondria, is converted to $\mathrm{H}_{2} \mathrm{O}_{2}$ by superoxide dismutases (SOD), which are the first and major line of defense against ROS. $\mathrm{H}_{2} \mathrm{O}_{2}$ accumulation is highly toxic for cells, and it is subsequently transformed to $\mathrm{H}_{2} \mathrm{O}$ and molecular oxygen by the catalase enzyme (CAT). Glutathione peroxidases (GPX) and thioredoxin reductases ( $T r x R$ ) also aid in the conversion from $\mathrm{H}_{2} \mathrm{O}_{2}$ to water. Independently, $\mathrm{H}_{2} \mathrm{O}_{2}$ is also converted to $\mathrm{OH}^{-}$. 
the NRF2/KEAP pathway mediated by fumarate accumulation and ERK5 activation [76].

Overexpression or knockout of the ROS metabolizing enzymes has helped in the understanding of the function and activity of the different groups of antioxidant enzymes, as well as how their dysregulation can lead to disease. For instance, SOD3 ablation in adult mice caused increased lung superoxide content, inflammation, respiratory acidosis and reached $85 \%$ mortality within six days [77]. SOD3 is usually repressed in the tumor microenvironment, but reexpression of the enzyme in tumor-associated endothelial cells improved tumor perfusion and selective chemotherapy delivery [78]. There are many other SOD enzymes involved in disease, as is the case of SOD1, which is linked to inherited amyotrophic lateral sclerosis (ALS) [79]. We find more examples in which re-introduction of a ROS detoxification enzyme leads to disease amelioration. The overexpression of catalase in a breast cancer model increased the sensitivity of the tumor cells to paclitaxel, etoposide and arsenic trioxide, redox-based chemotherapeutic drugs [80]. Catalase deficiency has also been linked to the development of type 2 diabetes mellitus [81], cardiac aging and hypertension [82], or increased DNA damage during UVB irradiation [83]. In contrast, catalase overexpression has been demonstrated to protect the mitochondria of insulinsecreting cells against ROS toxicity and cytokine-mediated cell destruction [84]. However, the presence of ROS detoxification enzymes is not always correlated to a positive outcome. In this regard, Gpx1 expression and activity have been shown to increase in mouse livers after the induction of hepatitis. Lee et al. (2016) reported that, in fact, Gpx1 KO mice presented an attenuation of liver injury by inhibiting cytokine production [85]. These disparate observations testify for a clear role of ROS detoxifying enzymes in multiple pathophysiological settings and emphasize how different ROS detoxification enzymes may play opposite roles depending on the level of oxidative stress and in the type of tissue.

\section{THE UNFOLDED PROTEIN RESPONSE}

To guarantee the appropriate folding, assembly and turnover of proteins under normal and stress conditions, cells modulate the levels of proteases and chaperones involved in protein quality control. In eukaryotes, the cytosol, ER and mitochondria are all exposed to nascent polypeptides, thus each compartment requires specific protein-folding machinery and responds differently upon unfolded polypeptides, signaling to the nucleus to induce the expression of organelle-specific chaperones. The unfolded protein response (UPR) encompasses, thus, a collection of signaling pathways that evolved to restore an efficient protein-folding environment. The mitochondrial UPR $\left(U P R^{\mathrm{mt}}\right)$, the endoplasmic reticulum UPR $\left(U P R^{E R}\right)$ and the cytosolic heat-shock response (HSR), exist as quality control mechanisms against proteostatic stress cues that put at risk cellular homeostasis, and that can lead, ultimately, to cell death and apoptosis.

\section{$U P R^{m t}$}

One of the first hints to the existence of a mitochondrial UPR was provided by the Hoogenraad laboratory in a simple yet pioneering experiment overexpressing OTC- $\Delta$ - a mutant form of the mitochondrial matrix protein Ornithine transcarbamylase - as a way to promote protein misfolding and aggregation. This artificial paradigm to induce variations in the stoichiometry of the mitochondrial- and nuclear-encoded proteins in the mitochondrial matrix led to the increased expression of HSP60 and CLPP (ATP-dependent caseinolytic protease proteolytic subunit) in cultured mammalian cells $[86,87]$. Coimmunoprecipitation analysis revealed that both HSP60 and CLPP were stably associated with OTC- $\Delta$, but not with the wild type OTC, suggesting a possible role of these stress-induced proteins in resolving misfolded proteins [87]. Furthermore, this response was shown to be organelle-specific, as the ER- and cytoplasmic-specific chaperones were not affected [86, 87]. Hence, it was established that the accumulation of misfolded proteins in mitochondria produces a mitochondrial stress response, known as the mitochondrial unfolded protein response $\left(U P R^{\mathrm{mt}}\right)$, characterized by the upregulation of nuclear genes encoding mitochondrial molecular chaperones and proteases, in order to ensure the functional integrity of the mitochondrial proteome [87]. However, it is not yet clear if the induction of the UPR ${ }^{\mathrm{mt}}$ per se is enough to reduce the abundance or aggregation of misfolded proteins. Similarly, it is not clear whether the removal of these aggregates is required for the potential recovery of mitochondrial function after UPR ${ }^{\mathrm{mt}}$.

Some of the factors triggering the UPR ${ }^{\mathrm{mt}}$ include mtDNA depletion, impaired mitochondrial protein quality control or OXPHOS dysregulations. These defects influence one another, as OXPHOS or mitochondrial proteostasis perturbations reduce the rate of protein import inside mitochondria by increasing the inner mitochondrial membrane (IMM) proton permeability, which consequently dissipates the proton gradient and causes precursor proteins to remain outside the mitochondria [ 88 , 89].

The mitochondrial genome encodes 13 proteins that are constituents of the OXPHOS respiratory complexes, but the rest of the mitochondrial proteome is encoded in nuclear genes, synthetized in the cytosol and imported to the different mitochondrial compartments via the TOM (translocase of the outer membrane) and TIM (translocase of the inner membrane) channels [90, 91]. Because the majority of proteins in mitochondria are synthesized by cytosolic ribosomes, proper protein translocation inside the organelle becomes vital for its function. Protein import and folding into the mitochondrial intermembrane space (IMS) relies on disulphide bond formation, and this is carried out by the mitochondrial disulphide relay machinery, using $\mathrm{O}_{2}$ in the process [92]. During stress conditions, such as hypoxia, uncontrolled ROS production or mismatched rates of protein import, mitochondria have developed protein folding assistance 
mechanisms to preserve proteostasis, as described below.

Although initially discovered in mammals [86], the elucidation of the UPR ${ }^{\mathrm{mt}}$ molecular mechanism has been mostly characterized in $C$. elegans due to the relative ease of using this organism to perform genetic screenings. In worms, the response is characterized by the action of regulators including the mitochondrial matrix protease CLPP, the ATP-binding cassette $(A B C)$ transporter HAF-1 and the basic leucine zipper (bZIP) transcription factor ATFS-1. Briefly, upon mitochondrial proteostatic stress, CLPP proteolytic activity degrades misfolded proteins in the mitochondrial matrix, and the small peptides are then transferred across the IMM via HAF-1. Afterwards, these peptides are moved through the outer mitochondrial membrane (OMM) by passive diffusion to the cytosol (Figure 3a). This activates ATFS-1, which translocates to the nucleus thanks to a nuclear localization sequence (NLS) and activates the ubiquitinlike protein UBL-5 to form a complex with the transcription factor DVE-1 [93]. ATSF-1 and DVE-1/UBL-5 then cooperatively regulate the transcription of mitochondrial chaperones including HSP60 and mtHSP70 [94]. Recent studies also demonstrate that chromatin is specifically remodelled during mitochondrial dysfunction to activate the $U P R^{m t}$ - responsive genes. The histone methyltransferase MET2 in concert with LIN65 promote global chromatin condensation, while the histone demethylases JMJD-3.1 and JMJD-1.2 maintain the promoters of UPR ${ }^{\mathrm{mt}}$ induced genes in a transcriptionally competent state, and this structure is further stabilized by the DVE-1/UBL5 complex to facilitate ATFS-1 access to chaperone promoters [95].

Other UPR ${ }^{\mathrm{mt}}$ response gene sets encode as well for mitochondrial proteases, ROS detoxification enzymes, and mitochondrial protein import components [96], aimed to restore mitochondrial homeostasis. Furthermore, metabolic adaptations inevitably take place during mitochondrial stress, as ATFS-1 also promotes the transcription of glycolysis genes, which aids sustaining ATP levels [97] and the mevalonate pathway [98], which feeds the synthesis of cholesterol, heme groups, coenzyme Q10 and steroid hormones [99]. Once mitochondrial function is restored, ATFS-1 is imported again into mitochondria, where it is degraded by the Lon protease. Thus, ATFS-1 accumulation on the cytosol upon impaired protein import efficiency acts as both a proteostatic sensor and a mitochondria-to-nucleus signaling mechanism. It should be noted, however, that the set of genes upregulated by the UPR ${ }^{\mathrm{mt}}$ in $C$. elegans is different to that of mammalian cells. This emphasizes that the mechanisms of proteostatic regulation differ between organisms and that equivalences between models should be taken with some caution. For instance, although some of the components of the pathway, such as the mitochondrial chaperones and the quality control protease CLPP were shown to be conserved from $C$. elegans to mammals, the closest mammalian homologs of DVE-1, SATB1 and SATB2, are unable to stimulate the UPR ${ }^{\mathrm{mt}}$ [100]. In addition, mammals possess several signalling paths and transcriptional regulators that might redundantly influence the response.

In mammals, the UPR ${ }^{\mathrm{mt}}$ is mediated by the CHOPC/EBP $\beta$ system $[87,101]$, in which the sensing of unfolded proteins is transmitted by a retrograde signaling to the nucleus, leading to the activation of the CHOP gene. The transcription factor C-Jun is activated via JNK2 and binds to the CHOP and C/EBP $\beta$ promoters, respectively, thanks to the presence of the AP-1 binding site (Figure 3b). Once expressed, the CHOP- C/EBP $\beta$ system binds to specific gene promoters, characterized by the presence of the CHOP binding site and two mitochondrial unfolded protein response elements (MURE1 and MURE2), promoting the transcription of UPR ${ }^{\mathrm{mt}}$-responsive genes. The bioinformatics approach by Aldridge et al. (2007) identified seven genes UPR ${ }^{\mathrm{mt}}$-responsive, including YMEL1L1, mitochondrial thioredoxin 2 (Trx2), NDUFB2 (subunit of complex I) or CLPP [101]. Nevertheless, CHOP specificity in the $U P R^{m t}$ is questionable, as its promoter contains both an $U P R^{E R}$ and an UPR ${ }^{\mathrm{mt}}$ response element [102]. Furthermore, CHOP can also be induced by other mitochondrial stresses unrelated to protein folding. Hence, the induction of CHOP should not be taken as a direct readout of $U P R^{\mathrm{mt}}[87,103]$. Interestingly, some studies point out to a matrix-specific UPR ${ }^{\mathrm{mt}}$ that senses excess of unfolded proteins in the IMS and that is independent of CHOP [104]. This was demonstrated through the overexpression of a mutant form of endonuclease $G$ (EndoG), an IMS-specific nuclease, that lead to the formation of aggregates in the mitochondrial IMS, which results in IMS stress [104] and ROS overproduction. ROSdependent AKT phosphorylation activated the estrogen receptor $\alpha(E R \alpha)[105,106]$, which promotes the expression of the IMS protease HTRA2, the nuclear respiratory factor NRF1, and the activity of the proteasome [107].

Induction of the integrated stress response (ISR) has also been reported to coordinate the UPR ${ }^{\mathrm{mt}}$ in mammals, in a mechanism dependent on the phosphorylation of the eukaryotic translation initiation factor 2 (elF $2 \alpha$ ) [108, 109]. Although elF $2 \alpha$ phosphorylation leads to inhibition of global protein synthesis, specific mRNAs can bypass this limitation if they have small open reading frames in their 5'UTR (uORFs), which is the case for the activating transcription factor 4 (ATF4), CHOP and the functional ortholog of ATFS-1, ATF5. ATF4 has been described to enhance ATF5 expression [110], which can contribute to transcriptional adaptations to mitochondrial stress [111]. In a complementary fashion to that of HAF-1 and ATFS-1, elF $2 \alpha$ can be activated by four different forms of cellular stress: PERK (ER stress), PRK (presence of double-stranded RNA), HRI (heme deficiency) and GCN-2 (amino acid starvation) [108]. Constitutive expression of a phosphomimetic 

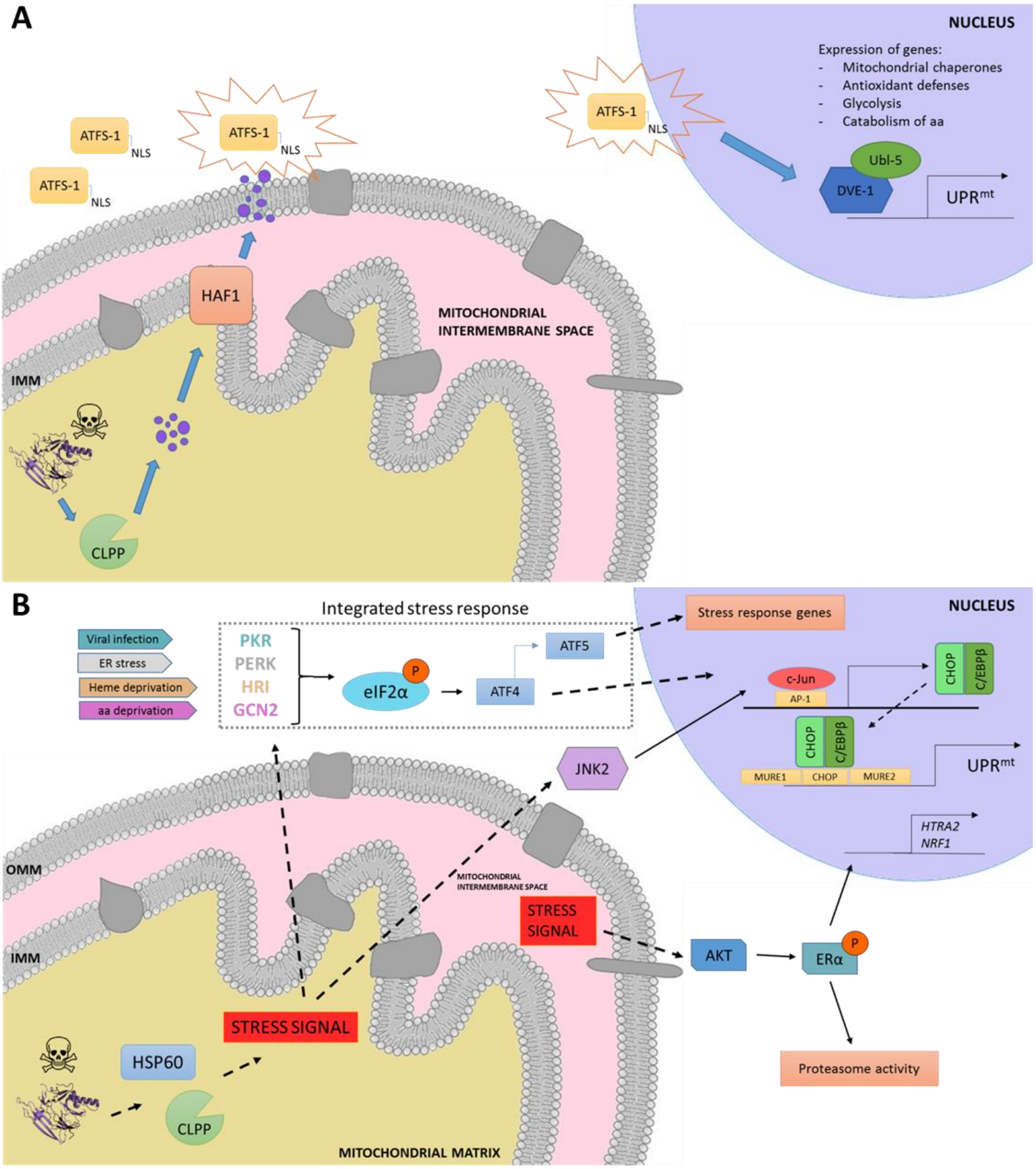

FIGURE 3: Overview of the UPR ${ }^{\mathrm{mt}}$ in worms and mammals. (A) UPR ${ }^{\mathrm{mt}}$ in C. elegans. When the capability of the mitochondria to process unfolded proteins is compromised, the mitochondrial unfolded protein response (UPR ${ }^{\mathrm{mt}}$ ) is activated. Upon mitochondrial stress, the protease CLPP degrades the excess of unfolded proteins, and the resulting fragments are moved across the inner mitochondrial membrane (IMM) to the intermembrane space, where they diffuse through passive diffusion to the cytoplasm. ATSF-1 import inside mitochondria is prevented, and its activation upon the sensing of the degraded peptides shuttles ATFS-1 to the nucleus, granted by the nuclear localization sequence (NLS). (B) Retrograde signaling in mammals upon proteotoxic stress. The excess of unfolded proteins is sensed by quality control proteases and chaperones such as HSP60 and CLPP, and the stress signal is processed via two different pathways, the activation of the CHOP gene via the JNK pathway and the induction of the integrated stress response (ISR), respectively. On the one hand, JNK2 processes the stress signal from the mitochondrial matrix to activate the transcription factor C-Jun, which binds to AP-1 elements and induces the expression of CHOP and C/EBP 3 . The CHOP-C/EBP $\beta$ complex then binds to the CHOP element, which is flanked by two mitochondrial unfolded protein response elements (MURE1 and MURE2), activating the transcription of UPR ${ }^{\mathrm{mt}}$ responsive genes. On the other hand, viral infection, ER stress, heme deprivation and amino acid insufficiency activate PRK, PERK, HRI and GCN2, respectively, giving rise to the phosphorylation of elF2 $\alpha$, the core of the ISR. This leads to the preferential translation of ISR-specific mRNAs, such as ATF4, the main effector of the ISR. ATF4 enhances the transcription of ATF5, leading consequently to the transcription of target genes. Moreover, a matrix-independent IMS- specific UPR ${ }^{\mathrm{mt}}$ has also been reported. Stress signals coming from the accumulation of unfolded proteins in the IMS leads to the AKT-mediated phosphorylation of ER $\alpha$, resulting in the expression of HTRA2, NRF1, and an increase in the activity of the proteasome. 
S49D mutation in elF2 $\alpha$ conferred dramatic effects, impairing growth, oxidative metabolism and reproduction in transgenic worms [112].

Moreover, several mitochondrial stress responses (MSRs) are induced by other factors different to protein misfolding and that can trigger the ISR. For instance, Tyynismaa et al. (2010) developed a mouse model carrying a mutation in TWINKLE - a mtDNA helicase - that lead to the accumulation of mtDNA deletion, resulting in respiratory chain deficiency and the induction of the MSR [113]. Interestingly, global gene expression patterns showed induction of pathways involved in amino acid starvation and lipid metabolism regulation, particularly Fgf21 [114]. Fgf21 was upregulated in the skeletal muscle of the mutant mice, correlated to small adipocyte size, low fat content in the liver and resistance to highfat diet [114]. This study exemplifies how mitochondrial stress responses, which are commonly activated upon pathogenesis of mitochondrial disorders, can lead to reprogrammed cellular metabolism. Further, the recent work by Quirós et al. (2017) showed the overlapping between the MSR and the ISR via the specific activation of ATF4, which resulted in the upregulation of pathways related to biosynthesis of amino acids, in particular serine [115]. The authors discussed that this increase in serine might be used to promote the synthesis of lipids and phospholipids, as these pathways were the most highly induced upon mitochondrial stress. All the above studies point out to the conclusion that mitochondrial stress responses might share effector pathways, irrespectively of the nature of the stress. Further work will be needed to fully understand how the specificity and threshold of the damage is determined.

Mitochondrial function is also altered by its communication with other cellular organelles, besides the nucleus. Mitochondria physical interaction with the ER has many functional implications, including calcium exchange or lipid transfer, but also targets the ER as one of the first sites when mitochondrial function is disrupted. The association between defective mitochondria and the ER has been demonstrated to increase ER stress, resulting in incorrect protein folding [116], source of neurodegenerative disorders such as Parkinson's disease.

\section{$U P R^{E R}$}

The accumulation of toxic, unfolded proteins in the ER leads to ER stress and the activation of the ER unfolded protein response $\left(U P R^{\mathrm{ER}}\right)$. The $U P R^{\mathrm{ER}}$ was the first stress response identified [117, 118], and because of this it is still often referred simply as the UPR. Different mechanisms seek to restore normal ER function by increased expression of ER-specific chaperones. In mammals, the IRE1, PERK and ATF6 mechanisms monitor correct ERspecific protein folding function through direct interaction with BiP (ER chaperone-binding immunoglobulin protein). These signaling pathways activate transcription and translational mechanisms that reduce global protein synthesis, increase ER protein-folding capacity, and promote the degradation of misfolded proteins [119]. Varia- tions exist in the key players of the UPR between organisms, which correlated with the level of evolution of their organelles. IRE1 - considered the most ancient UPR pathway - is present in budding yeast, plants, fungi and metazoans. Protozoans, however, do not have orthologues of IRE1. The activation mechanism of IRE1 has not been yet fully elucidated, although recent studies point out that post-translational modifications may determine its functionality, such as phosphorylation at Ser729 [120]. Although the activation mechanisms for IRE1, PERK and ATF6 differ, the three pathways can communicate with each other, as illustrated by the regulatory feedback of the XBP1-ATF6 axis [121, 122], or by the enhanced IRE1 $\alpha$-XBP1 signaling via PERK [123], which may enable cells to cope with various types and intensities of ER stress. Moreover, Bax and Bcl2 - which oligomerize in the OMM upon activation - can also localize to the ER upon ER stress. As compared to mitochondria, Bak depletes the ER of $\mathrm{Ca}^{+2}$ and induces Caspase 12 cleavage and consequently apoptosis [124]. These results point out to a co-regulation between the mitochondrial- and the ER-UPR. One of the critical connections between the ER and mitochondrial function is established by the direct connection between both organelles. Mitochondria are spatially and functionally organized in a network in close contact with the ER [125], and this contributes to mitochondrial uptake of $\mathrm{Ca}^{+2}$ released from the ER by inositol-1,4,5-triphosphate ( $\left.\operatorname{InsP}_{3}\right)$ and also sustains lipid biosynthesis, which occurs at sites of ER membranes attached to mitochondria that contain phospholipid and glycosphingolipid biosynthetic enzymes [126, 127].

Multiple models of mitochondrial dysfunction are characterized by ER stress. Elevated levels of free $\mathrm{Ca}^{+2}$ due to mitochondrial dysfunction have been linked to the induction of ER stress in a p38 MAPK-dependent manner, giving rise to aberrant insulin signaling and hepatic gluconeogenesis [128]. Ablation of Mfn2 - a key component in the mitochondrial fusion machinery localized in the OMM - triggers all three UPR ${ }^{\mathrm{ER}}$ and determines cell fate [129]. ER stress impacts, reciprocally, over mitochondrial proteostasis, as it is the case of the cytochrome C oxidase (COX) expression and assembly. Hori et al. (2002) demonstrated that suppression of protein synthesis due to ER stress had an effect on the assembly of the COX complex by disruption of the synthesis of COX subunits and ATP-dependent enzymes [130]. Moreover, suppression of PERK leads to the upregulation of the mitochondrial matrix proteins Lon, $\mathrm{mtHsp} 70$ and Yme1, and this aids proteostasis capacity. Physical and functional interactions between mitochondria and the ER are, thus, essential for cellular function and survival. Disruptions of ER-mitochondria tethering have been reported in human neurodegenerative disorders [131], which emphasizes that, rather than considering the two organelles separately, a better understanding of human pathologies can derive from studying the alterations in their crosstalk. 


\section{HSF}

The cytosolic UPR is mediated mainly by the heat-shock factor (HSF) family of proteins, maintaining proteinfolding homeostasis in the cytosol. In eukaryotes, ribosome-associated chaperones such as NAC (nascent chain associated complex) and RAC (ribosome associated complex) interact with the ribosome and bind to hydrophobic elements of newly synthesized polypeptides, facilitating folding or polypeptide transfer to downstream chaperones [132]. Stress-inducible cytosolic Hsp70 functions with Hsp40 to assist in the folding of $20 \%$ of newly synthesised polypeptides in an ATP-dependent manner $[133,134]$, and Hsp70 also helps in protein trafficking and degradation of misfolded proteins [135]. Finally, proteins that are unable to fold by chaperones are transferred to the chaperonin cages. Encapsulation has been suggested to accelerate the folding rate of the unfolded peptides over spontaneous folding. The TRiC (T-complex protein-1 Ring Complex; also called CCT) eukaryote chaperonin system promotes ATP-dependent folding of approximately $10 \%$ of the eukaryotic proteome [136], even though it is still not yet fully understood how TRiC is capable of discerning between non-folded substrates and the folded counterparts. Nuclear magnetic resonance (NMR), crosslinking-mass spectrometry and modeling approaches suggest that recognition codes in the polypeptide enable substrate recognition by TRiC [137]. Significantly, TRiC chaperonins have been linked to numerous pathologies, such as neuropathies [138], oncogenesis [139], or agerelated diseases [140, 141]. A connection between the cytosolic UPR and mitochondrial function has recently been described by means of the heat shock factor 1 (HSF1), which is a quality control regulator with a role in systemic energy sensing and metabolic adaptation to nutrient availability [142]. The article by Qiao et al. (2017) reported that, in the absence of HSF1, the levels of NAD ${ }^{+}$and ATP are not sustained in hepatic cells, and this increased protein acetylation and impaired mitochondrial integrity. Furthermore, the activity of HSF1 upon low levels of mitochondrial stress regulates cytoplasmic proteostasis and healthspan in worms [143], emphasizing - as it occurred for the UPR ${ }^{E R}$ the intricate regulation between the cytosolic UPR and mitochondrial function.

Damaged mitochondria that are not salvageable by the UPR can be identified and specifically degraded through a process called mitophagy (originally, mitophagocytosis). This process helps eliminate the impaired mitochondria that could harm the rest of the functional network, and will be discussed in the next section.

\section{MITOCHONDRIAL DYNAMICS AND MITOPHAGY: EASY COME, EASY GO}

Mitochondrial dynamics are the repetitive cycles of fission and fusion of the mitochondrial network. These are highly orchestrated events influenced by a variety of physiological and environmental cues. For instance, nutrient supply: nutrient overload is linked to a fragmentation of the mitochondrial network, while mitochondria elongate under starvation [144]. Furthermore, prior to mitosis, mitochondria go through fission events to guarantee an equal distribution to the daughter cells. The balance between fission and fusion activities will determine the architecture of the mitochondrial network and influences multiple mitochondrial functions, including respiratory coupling, calcium buffering or apoptosis. In this regard, the disruption of mitochondrial dynamics can give rise to a wide range of health and metabolic diseases, including diabetes and obesity [145, 146], as well as heart failure [147], Alzheimer disease [148-151], Parkinson disease [152, 153], and agerelated physiological decline [154, 155].

Fission and fusion events act as a quality control mechanism by removing defective mitochondria or by selecting the organelles with the optimal matrix metabolites, intact mtDNA copies and mitochondrial membrane components. This interplay between mitochondrial dynamics and mitophagy - the selective removal of mitochondria by the autophagic machinery - assures the homeostasis of the cell. When one of these elements fails, dysfunctional mitochondria are not properly removed from the cellular pool, generally leading to higher amounts of ROS production and increased susceptibility to release cytochrome $c$ and apoptosis-inducing factor (AIF) [156, 157].

Generally, mitochondrial fragmentation precedes mitophagy as mitochondria that are smaller are easier to be engulfed by the autophagosomes (APs) [158-162]. APs fuse with lysosomes and acquire acid hydrolases, which finally degrade the engulfed mitochondria. Previous studies indicate that fission is the main trigger of membrane depolarization in mitochondria. Twig et al. (2008) showed, by measuring the bioenergetic profile during fusion/fission events in COS7 and INS1 cells, that mitochondria tend to maintain a stable membrane potential $\Delta \psi_{\mathrm{m}}$ (within \pm 2.7 $\mathrm{mV})$ [163]. However, fission events generate large changes in $\Delta \psi_{\mathrm{m}}$ and, in the majority of the cases, one daughter mitochondria will be depolarized while the other will hyperpolarize $\left(\Delta \psi_{\mathrm{m}}\right.$ difference $\left.>5 \mathrm{mV}\right)$, resulting in asymmetric daughter mitochondria. Depolarization below a certain $\Delta \psi_{\mathrm{m}}$ is associated with impaired mitochondrial function and acts as the trigger for mitophagy [163, 164].

The perspective of mitochondrial fission acting upstream of mitophagy was validated by genetic manipulation of the pro-fission proteins Fis1 (Fission 1 protein) and Drp1 (Dynamin-related protein 1). The mammalian Drp1 is a GTPase that localizes mostly in the cytosol, but that can cycle on and off the OMM, where it can be docked by a set of different proteins, such as Fis1, the mitochondrial fission factor (Mff) or MiD49/51 [165]. Once recruited to the OMM, Drp1 oligomerizes and constricts the mitochondria, which gives rise to two daughter organelles [166]. Knockdown of Fis1 (by siRNA) or overexpression of a dominant negative Drp1 isoform (Drp1 K38A) resulted in the reduction of the number of mitochondrial-containing autophagosomes, but not in the total number of lysosomes [163, 167]. As degradation of dysfunctional mitochondria was impaired, levels of mitochondrial protein oxidation were increased with no significant ROS overproduction. Never- 
theless, some studies indicate that mitophagy can also occur independently of Drp1 activity upon proteotoxic stress [168], illustrating a complex interplay between fission and mitophagy that still needs to be clarified.

Following mitochondrial fission and depolarization, Parkin and PINK1 (PTEN-induced putative kinase 1) are recruited to the OMM to tag the organelle for mitophagy. PINK1 is a serine/threonine kinase that identifies and targets specific mitochondria for degradation. Healthy mitochondria maintain a stable membrane potential that facilitates the import of PINK1 into the mitochondrial matrix, where it is cleaved and degraded [169]. The proteolysis of PINK1 is mediated by the IMM-associated PARL protease, and regulated by the recently described SPY complex [170]. However, upon impaired mitochondrial protein import, severely damaged mitochondria lack sufficient membrane potential to translocate PINK1, which is then stabilized in the OMM, recruiting Parkin from the cytosol. Parkin is an E3 ubiquitin ligase that, during mitophagy, polyubiquitinates multiple proteins to direct towards degradation. Parkin substrates include mitofusins Mfn1 and Mfn2, which are large GTPases that promote OMM fusion [171]. Ubiquitination of $\mathrm{Mfn} 1 / 2$ prevents the refusion of the damaged mitochondria with the healthy mitochondrial network, and also signals for the recruitment of ubiquitinbinding proteins such as p62/SQSTM1, which mediate the aggregation into APs [172]. p62/SQSTM1 acts as an ubiquitin-binding scaffold protein that undergoes disulfide bondlinked self-aggregation to interact with LC3 on autophagic membranes leading the co-delivery with its cargoes to the autophagosome [173]. Nevertheless, mitophagy can occur independently of p62/SQSTM1, as recently reported by the Youle lab [174]. Even though p62/SQSTM1 was required for Parkin-induced mitochondrial clustering, acute loss of p62 in HeLa cells by siRNA did not prevent Parkin-induced mitophagy, which indicates that p62/SQSTM1- independent mechanisms may mediate some events of the mitophagic process downstream of Parkin [174].

Mitochondrial ATP status and $\Delta \psi_{\mathrm{m}}$ depolarization can also act as regulators of mitophagy by promoting Opa1 cleavage. Opa1 regulates mitochondrial fusion and cristae structure in the IMM $[175,176]$. Mammalian cells express eight Opa1 splice forms [177], a proportion of which is constitutively cleaved by the YME1L protease, generating fusion-competent mixed populations of long and short OPA1 (L-OPA1 and S-OPA1, respectively) $[178,179]$. Upon mitochondrial membrane depolarization, the long isoforms of Opa1 (L-OPA1) undergo cleavage by the protease OMA1, rendering the membrane incapable to sustain fusion. Interestingly, mitophagy was significantly impaired in OMA1 deficient cells, indicating that cleavage of L-OPA1 acts as a crucial control point for mitophagy [180].

Overall, sustained membrane depolarization results in cleavage of Opa1 in the IMM, accumulation of PINK1/Parkin and ubiquitination of $\mathrm{Mfn} 1 / 2$ in the OMM, and this promotes the damaged and targeted mitochondria to be engulfed by the AP (Figure 4). Nevertheless, it should also be noted that mitophagy can be modulated in a
PINK1/Parkin - independent manner, upon hypoxia or targeting by other OMM proteins. For instance, Nix is an OMM receptor that activates the apoptotic machinery and favors the elimination of mitochondria during red blood cell differentiation and elimination in erythrocytes [181]. Nix contains a LIR (LC3-interacting region) and, upon activation, Nix and BNIP3 promote the opening of the mitochondrial transition pore, which results in depolarization of the organelle and recruitment of LC3/GABARAPs for autophagosome formation [182, 183]. In addition to Nix, FUNDC1 - an integral OMM protein - modulates mitophagy in response to hypoxia by the increased affinity between its LIR motif and LC3 on AP membranes that results after FUNDC1 phosphorylation by ULK1 [184]. FUNDC1mediated mitophagy has been recently demonstrated to play an essential role in cardiac function in vivo [185]. Iron chelators can also generate a mitophagy response in the absence of PINK1, yet the mechanism requires to be further elucidated [186]. Of note, basal mammalian mitophagy occurs independently of PINK1 in tissues with high metabolic demand, which could indicate that mammalian cells have multiple mitophagy pathways that can be triggered in response to diverse stress stimuli [187].

Interestingly, the UPR ${ }^{\mathrm{mt}}$ and the mitophagic events could be connected through a common stressor mechanism which might benefit the mitochondrial population that can still be recovered over the one that is targeted for mitophagy. While mitophagy limits the damage to defective mitochondria, stress responses such as the UPR ${ }^{\mathrm{mt}}$ facilitate the recovery of salvageable mitochondria, ultimately yielding a healthier mitochondrial network [91]. As Pickles (2018) suggested, the mitochondria that sends ATFS-1 to the nucleus may not benefit from the action of the chaperones and proteases that could be imported into more fit mitochondria, leaving the most damaged mitochondria for mitophagy [189].

Although dysfunctional mitochondria that are fragmented are more likely to be targeted for mitophagy, some species-dependent exceptions can be found [161, 190]. On the other hand, daughters of mitochondrial fission have unequal probabilities of undergoing subsequent fusion Fusion preferentially occurs between mitochondria with higher $\Delta \psi_{m}$, as they are presumed to have better quality that can help maintain the activity of the network. This establishes mitophagy and fusion as two competing events determining the fate of the mitochondria.

\section{MITOCHONDRIAL FUSION AS A SELECTIVE RESCUE MECHANISM}

Mitochondrial fusion allows the diffusion of matrix and membrane components. This serves as a 'compensatory' mechanism to equilibrate proteins, complexes and metabolites from one healthy mitochondria to a second one that might be damaged. Hence, fusion may recruit dysfunctional mitochondria into the active pool, instead of being eliminated by mitophagy.

Mitochondrial fusion contributes to the maintenance of a stable $\Delta \psi_{\mathrm{m}}$, homogeneity of the components of the elec- 
tron transport chain and stability of mtDNA nucleoids. Heteroplasmic cells - with both normal and mutant mtDNA can accumulate mutations to a threshold level before respiratory activity is affected and the mitochondria is targeted for mitophagy. Reaching this turnover would be relented by the compensatory mechanisms that mitochondrial fusion brings by complementing mtDNA from healthy organelles. Real time imaging experiments by Yang et al. (2015) allowed the visualization of mtDNA nucleoid dynamics after complete fusion of the mitochondria. Rho0 cells recovered their $\Delta \psi_{\mathrm{m}}$ after fusion with wild type cells, and this was prevented by the deletion of $M f n 1 / 2$ and Opa1. Interestingly, motility of the newly fused mitochondria was increased [191], which would allow specific positioning of the mitochondria for different metabolic and cellular processes. Fusion compensatory function was also validated in skeletal muscle of Mfn1/2-deficient mice [192, 193]. The rate of mtDNA point mutations and deletions was increased in these mice, events preceded by physiological abnormalities and muscle atrophy. Moreover, stimulation of mitochondrial motility by overexpression of Miro-1 - a mitochondrial Rho-GTPase that promotes mitochondrial movement along microtubules - increases mitochondrial fusion in neurons [194]. Mitochondria proximity favored by $\mathrm{Ca}^{+2}$ oscillations also contributes to increased fusion rate [195]: the closer two mitochondria are, the better chances for them to fuse. Fusion events are also dependent on the intermediates of the metabolic processes taking place in the mitochondrial matrix, as observed by Cavellini et al. (2017), reporting that unsaturated fatty ac- ids impede outer membrane fusion, establishing a mechanistic crosstalk between mitofusins and fatty acid desaturation [196]. Similarly, high OXPHOS levels can stimulate mitochondrial inner membrane fusion by increased efficiency of YME1L in the proteolytic processing of Opa1 [197].

Then, what determines whether mitochondria should be rescued by fusion from autophagy? Redistribution has an impact upon mitochondria function. Non-selective fusion would contribute to damaged mitochondria impairing the activity and efficiency of the healthy population. It was demonstrated by Twig et al. (2008) that, after fission, fusion occurs preferentially between mitochondria with higher $\Delta \psi_{m}$, as compared to the subpopulation of nonfusing mitochondria that presented depolarized $\Delta \psi_{\mathrm{m}}$. The depolarization of an individual mitochondrion is also accompanied by reduced levels of Opa1, and this decreases its probability of undergoing fusion [163]. These findings would indicate that fusion is a selective and exclusive process for hyperpolarized mitochondria, rather than an unselective rescue mechanism. Thus, these two traits, reduced $\Delta \psi_{\mathrm{m}}$ and loss of Opa1 activity, would promote targeting of mitochondria for autophagy. The selectivity of mitochondrial fusion not only prevents the migration of damaged components into active mitochondria, but is also an isolation step that creates a segregated population that is available for autophagy (Figure 4).

Nevertheless, fusion is not only a compensatory, but also a protective mechanism of mitochondria against metabolic and stress challenges, carried out by modification of the key players in the fusion machinery. Upon starvation,

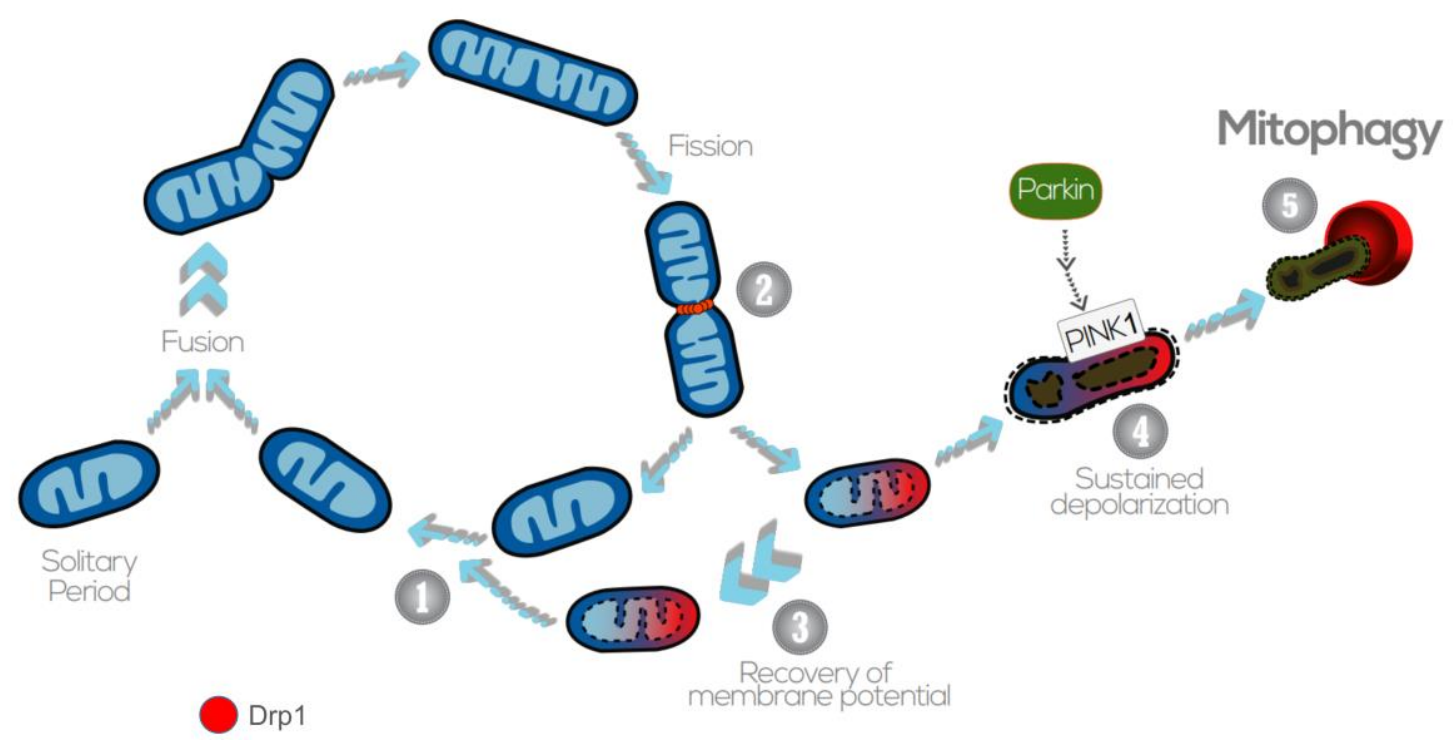

FIGURE 4: The interplay between mitochondrial dynamics and mitophagy. The mitochondrial network shifts between continuous cycles of fusion and fission, each of which can last seconds to minutes. Fission of mitochondria (2) is carried out by the Drp1 GTPase, which is recruited to the OMM from the cytosol. Fission events often generate daughter units with different $\Delta \psi_{\mathrm{m}}$ : on the one hand, some mitochondria are depolarized, but the $\Delta \psi_{\mathrm{m}}$ can be restored (3) by fusion with other mitochondria (1). After solitary periods, mitochondria might also fuse if the membrane potential is above a certain threshold. On the other hand, sustained $\Delta \psi_{\mathrm{m}}$ depolarization triggers cleavage of Opa1, reduction in Mfn capacity and accumulation of PINK1/Parkin in the OMM (4). This targets single dysfunctional mitochondrion to mitophagy (5), where it is engulfed by the autophagosome. Image adapted from Twig G. and Shirihai O.S. (2011) [188]. 
the increase in cAMP levels activates PKA, which phosphorylates Drp1 at Ser637 and keeps it in the cytosol, leading to unopposed mitochondrial fusion. Elongated mitochondria are spared from autophagic degradation, present higher oligomerization of ATPase and increased efficiency of ATP production. Therefore, mitochondrial elongation during starvation protects cells from death [144]. Furthermore, mitochondrial fusion after fasting eliminates oxidative stress via association of Mfn1 with the protein deacetylase HDAC6, which leads to Mfn1 deacetylation and activation [144]. Accordingly, HDAC6 knockout mice showed impaired mitochondrial fusion capacity upon glucose deprivation, resulting in mitochondrial degeneration, excessive production of ROS and oxidative damage in muscle [144].

Mitochondrial fusion has been suggested to provide a new treatment for mitochondria-related diseases such as diabetes, muscular dystrophies or neurodegenerative disorders, hence the increasing interest in developing activators of mitochondrial fusion [198]. In this regard, leflunomide - a drug approved to treat rheumatoid arthritis - has recently been documented to increase Mfn2 expression and mitochondrial fusion [199]. A recent report indicates that the conformation of $\mathrm{Mfn} 2$ heptad repeat domains is critical for Mfn2 GTPase activity. A close conformation is fusion incompetent, whereas an open conformation favors mitochondrial fusion. This open conformation can be induced by a competing peptide analogous to amino acids 367 to 384 within the $\mathrm{Mfn} 2$, resulting in the activation of Mfn2 and enhanced mitochondrial fusion. This new class of mitofusin agonists have been shown to ameliorate mitochondrial motility and depolarization in neurological disease models [200]. These works bring hope on the therapeutic possibilities of enhancing mitochondrial fusion in models characterized by fragmented, depolarized mitochondria.

Therefore, the elimination of damaged mitochondria by mitophagy and the elongation of the functional mitochondrial network by fusion could act as complementary processes to guarantee cell homeostasis and disease prevention. The choice of one or another to preserve mitochondrial health might depend on multiple parameters, including the degree of mitochondrial damage, the basal mitochondrial turnover rate or the intrinsic ability of the tissue/cell type to mobilize mitochondria for degradation.

\section{MITOCHONDRIAL BIOGENESIS}

Mitochondrial biogenesis is the process of increasing cellular mitochondrial mass. In most cases, mitochondrial biogenesis occurs in response to energy deficit, triggered either by increased cellular energy demand or by impaired ATP synthesis. Hence, it is not surprising that both situations share, at least in part, common mechanisms to increase mitochondrial copy number.

One possible starting point for mitochondrial biogenesis in situations of energy stress might be found in the activation of the AMP-activated protein kinase (AMPK). AMPK is a heterotrimeric enzyme composed by an $\alpha, \beta$ and $\gamma$ subunit, all of which can be present as different isoforms [201]. The $\gamma$ subunit acts as a sensor for the AMP/ATP ratio [201], providing AMPK an extremely refined capacity to respond to alterations in the cellular energy status. Upon activation, AMPK - or any of its eukaryote homologs - acts as a master metabolic controller in the cell [202]. In particular, AMPK shuts down most energy consuming programs not necessary for the immediate survival of the cell, including cellular division, cellular growth and most anabolic paths. On the other side, AMPK activates multiple cellular processes aimed to enhance energy production, such as increasing glucose uptake and glycolytic and fatty acid oxidation fluxes. Interestingly, AMPK activation can also trigger long-term adaptations, being mitochondrial biogenesis one of its defining features [203].

AMPK influences mitochondrial biogenesis, in part but not exclusively, through the activation of the transcriptional coactivator PGC-1 $\alpha$ (peroxisome proliferator activator receptor gamma coactivator $1 a)$. PGC- $1 \alpha$ was originally described as a cold-induced transcriptional coactivator in brown adipose tissue [204], but has been later certified as a master regulator of mitochondrial biogenesis [205]. This way, AMPK activation enhances mitochondrial and lipid oxidation markers in most cells tested to date. AMPK activators, however, failed to enhance mitochondrial-related gene expression and protein markers content in PGC-1 $\alpha$ deficient models $[206,207]$. Several mechanisms by which AMPK influences PGC-1 $\alpha$ have been proposed. First, AMPK activation can lead to a transcriptional increase in PGC-1 $\alpha$ levels $[208,209]$. Second, it was described that AMPK can directly phosphorylate and activate PGC- $1 \alpha$ coactivation properties [207]. It has also been proposed that the phosphorylation of PGC- $1 \alpha$ by AMPK might not trigger activation per se, but might alter the ability of PGC-1 $\alpha$ to interact with other proteins [210]. Finally, there is evidence suggesting that the direct phosphorylation of nuclear receptors and transcription factors by AMPK could influence the recruitment of PGC-1 $\alpha$ [211]. Most of these actions are not necessarily contradictory and could take place simultaneously.

Interestingly, AMPK influences the activity of another key regulator of cellular metabolism and mitochondrial function, the $N A D^{+}$-dependent protein deacylase SIRT1 $[210,212]$. The $\mathrm{Km}$ of SIRT1 for $\mathrm{NAD}^{+}$is high enough to make physiological intracellular levels of $\mathrm{NAD}^{+}$rate-limiting for SIRT1 activity [213]. This transforms SIRT1 into a potential $\mathrm{NAD}^{+}$sensor in the cell, hence responding to metabolic and oxidative stress challenges. AMPK has been shown to increase intracellular $\mathrm{NAD}^{+}$levels through metabolic rewiring upon fatty acid availability [210] and through transcriptional means [212], leading to SIRT1 activation. SIRT1, in turn, can deacetylate and activate PGC-1 $\alpha$ as well, leading to its activation [214]. In fact, AMPK-induced PGC-1 $\alpha$ phosphorylation has been proposed to serve as a way to facilitate PGC-1 $\alpha$ recognition by SIRT1 [210]. SIRT1 can also deacetylate other transcription factors and nuclear receptors controlling mitochondrial and fatty acid-related gene expression, $\mathrm{O}_{2}$ delivery or oxidative stress defenses, includ- 
ing PPAR $\alpha$, ERR $y$ and Forkhead-O-box transcription factors [213].

PGC-1 $\alpha$, however, is a nuclear coactivator, and mitochondrial biogenesis requires the replication and transcription of the mitochondrial genome. Bringing light into these issues, it was shown that the nuclear expression of the mitochondrial transcription factor A (TFAM), the key controller of mitochondrial DNA replication, is controlled via the nuclear respiratory factors 1 and 2 (NRF-1 and NRF-2) [215]. In fact, NRF-1 and NRF-2 bind to most of the promoters encoding for subunits of the mitochondrial respiratory chain [215].

AMPK exemplifies how a mitochondrial-related cue (energy balance) can be transformed into a metabolic adaptation. Nevertheless, mitochondrial biogenesis and PGC- $1 \alpha$ can be controlled through other means, for examples in situations of cancer or cellular proliferation [216]. Similarly, mitochondrial biogenesis cohabitates with other responses. For example, SIRT1 activation has been shown to trigger the $U R^{\mathrm{mt}}$ [217] which makes sense, as mitochondrial repair and biogenesis could constitute coordinated activities aimed to ensure mitochondrial fitness. Finally, mitochondrial biogenesis is not solely controlled by PGC-1 $\alpha$. Indeed, PGC-1 $\alpha$ deficiency in mice does not lead to major impairments in baseline mitochondrial function, and multiple eukaryote species and organisms, including yeast or worms, do not have PGC-1 $\alpha$ homologs, yet they can trigger mitochondrial biogenesis in response to nutrient availability. Nevertheless, while multiple paths might control the expression of mitochondrial-related genes, PGC-1 $\alpha$ might have appeared as a key modulator to achieve flexible solutions.

\section{CONCLUDING REMARKS}

Mitochondria are a key source for fuel and intermediate metabolites that are critical for cellular proliferation, differentiation, growth and function. The clear link between mitophagy and human diseases suggests a potential applicability of this process as a therapeutic target. However, some aspects need to be taken into consideration for the development of therapeutic strategies, including the tissue to be targeted or the severity of the disease. In physiological conditions, mitochondrial turnover takes place at very different rates depending on the tissue examined, and may even vary in the mitochondrial population of tissues of the same type [218]. This suggests that the key players in mitophagy and mitochondrial dynamics regulation could be dependent on the tissue and stimuli they are exposed to.

The different mechanisms ensuring mitochondrial quality control may gradually enter into scene, starting by basic defense systems such as the antioxidant responses against oxidative damage resulting from increased production of ROS. When these defenses are not sufficient and affect protein function and folding, mitochondria communicates to the nucleus to activate the unfolded protein response mediated by chaperones and proteases to restore protein homeostasis. Mitochondrial dynamics and mitophagy will also act reciprocally to maintain the quality, not just of individual organelles, but of the entire mitochondrial net- work. When this process is compromised, different pathologies arise, out of the accumulation of dysfunctional mitochondria or defective fusion/fission mediators. It must be clarified, however, that many of these mechanisms might occur simultaneously in a mitochondrial population, or even in the same mitochondrion. The boundaries and independence of these responses are therefore unclear. Similarly, some mitochondrial stress responses, such as the mammalian UPR $^{\mathrm{mt}}$ are still too vaguely defined. It will be important to define a clear standardization in the evaluation of UPR ${ }^{\mathrm{mt}}$ as, in fact, most works do not characterize mitochondrial protein aggregation.

Studying organelles in isolation has been indispensable for constructing our main body of knowledge on mitochondrial physiology. However, mitochondria do not behave as isolated entities in the cytosol, but as signaling organelles that communicate continuously with other cellular membranes and within themselves. Mitochondria impact nuclear gene expression by retrograde signaling, but also influence metabolite transfer through the physical contact sites with other organelles, such as the ER, lipid droplets, peroxisomes and lysosomes [219]. Decoding the intricate network of relations and responses elicited by mitochondria does not only constitute a riveting scientific challenge, but also the opening of new potential understanding for therapeutic approaches. Further, the very different behavior and characteristics of mitochondria in each tissue constitute a promising way to approach tissuespecificity in potential mitochondrial treatments. Recent findings even demonstrate that within a single cell there might be specific mitochondrial populations with dedicated bioenergetic capacities [220]. Hence, to understand the therapeutic potential around mitochondria, we will need to understand their identity and function, but also the time and space in which they participate within the cell life.

\section{ACKNOWLEDGMENTS}

$\mathrm{MV}$ - A and CC are funded by the EU Marie Skłodowska Curie ITN-ChroMe (H2020 - MSCA - ITN - 2015 - ChroMeproject number 675610). The authors would like to thank the Canto group, Ann-Kristin Hov and Margherita Springer for helpful suggestions.

\section{CONFLICT OF INTEREST}

MV - A and CC are employees of the Nestlé Institute of Health Sciences S.A.

\section{COPYRIGHT}

(C) 2018 Valera-Alberni and Canto. This is an open-access article released under the terms of the Creative Commons Attribution (CC BY) license, which allows the unrestricted use, distribution, and reproduction in any medium, provided the original author and source are acknowledged.

Please cite this article as: Miriam Valera-Alberni and Carles Canto (2018). Mitochondrial stress management: a dynamic journey. Cell Stress2 (10): 253-274. doi: 10.15698/cst2018.10.158 


\section{REFERENCES}

1. Picard M, Wallace DC, Burelle Y (2016). The Rise of Mitochondria in Medicine. Mitochondrion 30(2016): 105-116. doi: 10.1016/j.mito.2016.07.003

2. Gruber J, Schaffer S, Halliwell B (2008). The mitochondrial free radical theory of ageing - Where do we stand? Front Biosci 13: 65546579. doi: $10.2741 / 3174$

3. Sameer SK, Carles C (2017). Mitochondrial Post-translational Modifications and Metabolic Control: Sirtuins and Beyond. Curr Diabetes Rev 13(4): 338-351. doi: 10.2174/1573399812666160217122413

4. Chandel NS (2014). Mitochondria as signaling organelles. BMC Biology 12(1): 34. doi: 10.1186/1741-7007-12-34

5. Liu X, Kim CN, Yang J, Jemmerson R, Wang X (1996). Induction of Apoptotic Program in Cell-Free Extracts: Requirement for dATP and Cytochrome c. Cell 86(1): 147-157. doi: 10.1016/S00928674(00)80085-9

6. Hill S, Sataranatarajan K, Remmen HV (2018). Role of Signaling Molecules in Mitochondrial Stress Response. Front Genet 9: 225. doi: 10.3389/fgene.2018.00225

7. Okada AK, Teranishi K, Lobo F, Isas JM, Xiao J, Yen K, Cohen P, Langen R (2017). The Mitochondrial-Derived Peptides, HumaninS14G and Small Humanin-like Peptide 2, Exhibit Chaperone-like Activity. Sci $\operatorname{Rep} 7(1)$ : 7802. doi: 10.1038/s41598-017-08372-5

8. Lee C, Zeng J, Drew Brian G, Sallam T, Martin-Montalvo A, Wan J, Kim S-J, Mehta H, Hevener Andrea L, de Cabo R, Cohen P (2015). The Mitochondrial-Derived Peptide MOTS-c Promotes Metabolic Homeostasis and Reduces Obesity and Insulin Resistance. Cell Metab 21(3): 443-454. doi: 10.1016/j.cmet.2015.02.009

9. Cobb LJ, Lee C, Xiao J, Yen K, Wong RG, Nakamura HK, Mehta HH, Gao Q, Ashur C, Huffman DM, Wan J, Muzumdar R, Barzilai N, Cohen P (2016). Naturally occurring mitochondrial-derived peptides are agedependent regulators of apoptosis, insulin sensitivity, and inflammatory markers. Aging 8(4): 796-808. doi: 10.18632/aging.100943

10. Chai G-S, Duan D-X, Ma R-H, Shen J-Y, Li H-L, Ma Z-W, Luo Y, Wang L, Qi X-H, Wang Q, Wang J-Z, Wei Z, Mousseau DD, Wang L, Liu G (2014). Humanin attenuates Alzheimer-like cognitive deficits and pathological changes induced by amyloid $\beta$-peptide in rats. Neurosci Bull 30(6): 923-935. doi: 10.1007/s12264-014-1479-3

11. Guo B, Zhai D, Cabezas E, Welsh K, Nouraini S, Satterthwait AC, Reed JC (2003). Humanin peptide suppresses apoptosis by interfering with Bax activation. Nature 423(6938): 456-461. doi: 10.1038/nature01627

12. Widmer RJ, Flammer AJ, Herrmann J, Rodriguez-Porcel M, Wan J, Cohen P, Lerman LO, Lerman A (2012). Circulating humanin levels are associated with preserved coronary endothelial function. Am J Physiol Heart Circ Physiol 304(3): H393-H397. doi: 10.1152/ajpheart.00765.2012

13. Ikonen $M$, Liu B, Hashimoto $\mathrm{Y}$, Ma L, Lee K-W, Niikura T, Nishimoto I, Cohen P (2003). Interaction between the Alzheimer's survival peptide humanin and insulin-like growth factor-binding protein 3 regulates cell survival and apoptosis. Proc Natl Acad Sci U S A 100(22): 13042-13047. doi: 10.1073/pnas. 2135111100

14. Sreekumar P, Hinton D, Kannan R (2017). Endoplasmic reticulummitochondrial crosstalk: a novel role for the mitochondrial peptide humanin. Neural Regen Res 12(1): 35-38. doi: 10.4103/16735374.198970

15. Kim KH, Son JM, Benayoun BA, Lee C (2018). The MitochondrialEncoded Peptide MOTS-c Translocates to the Nucleus to Regulate Nuclear Gene Expression in Response to Metabolic Stress. Cell Metab 28(3): 516-524.e517. doi: 10.1016/j.cmet.2018.06.008
16. Katada S, Imhof A, Sassone-Corsi P (2012). Connecting Threads: Epigenetics and Metabolism. Cell 148(1): 24-28. doi: 10.1016/j.cell.2012.01.001

17. Takahashi H, McCaffery JM, Irizarry RA, Boeke JD (2006). Nucleocytosolic Acetyl-Coenzyme A Synthetase Is Required for Histone Acetylation and Global Transcription. Mol Cell 23(2): 207-217. doi: 10.1016/j.molcel.2006.05.040

18. Grant PA, Duggan L, Côté J, Roberts SM, Brownell J, Candau R, Ohba R, Owen-Hughes T, Allis C, Winston F, Berger S, Workman J (1997). Yeast Gcn5 functions in two multisubunit complexes to acetylate nucleosomal histones: Characterization of an Ada complex and the SAGA (Spt/Ada) complex. Genes Dev 11(13): 1640-1650. doi: 10.1101/gad.11.13.1640

19. Cai L, Sutter Benjamin M, Li B, Tu Benjamin P (2011). Acetyl-CoA Induces Cell Growth and Proliferation by Promoting the Acetylation of Histones at Growth Genes. Mol Cell 42(4): 426-437. doi: 10.1016/j.molcel.2011.05.004

20. Wellen KE, Hatzivassiliou G, Sachdeva UM, Bui TV, Cross JR, Thompson CB (2009). ATP-Citrate Lyase Links Cellular Metabolism to Histone Acetylation. Science 324(5930): 1076. doi: 10.1126/science.1164097

21. Mews P, Donahue G, Drake AM, Luczak V, Abel T, Berger SL (2017). Acetyl-CoA synthetase regulates histone acetylation and hippocampal memory. Nature 546: 381-386. doi: 10.1038/nature22405

22. Tahiliani M, Koh KP, Shen $Y$, Pastor WA, Bandukwala $H$, Brudno $Y$, Agarwal S, Iyer LM, Liu DR, Aravind L, Rao A (2009). Conversion of 5 Methylcytosine to 5-Hydroxymethylcytosine in Mammalian DNA by MLL Partner TET1. Science 324(5929): 930-935. doi: 10.1126/science.1170116

23. Mikkelsen TS, Ku M, Jaffe DB, Issac B, Lieberman E, Giannoukos G, Alvarez $P$, Brockman W, Kim T-K, Koche RP, Lee W, Mendenhall E, O'Donovan A, Presser A, Russ C, Xie X, Meissner A, Wernig M, Jaenisch $R$, Nusbaum C, Lander ES, Bernstein BE (2007). Genome-wide maps of chromatin state in pluripotent and lineage-committed cells. Nature 448(7153): 553-560. doi: 10.1038/nature06008

24. Zhang J, Wang X, Vikash V, Ye Q, Wu D, Liu Y, Dong W (2016). ROS and ROS-Mediated Cellular Signaling. Oxid Med Cell Longev 2016:4350965. doi: 10.1155/2016/4350965

25. Finkel T (1998). Oxygen radicals and signaling. Curr Opin Cell Biol 10(2): 248-253. doi: 10.1016/S0955-0674(98)80147-6

26. Sena Laura A, Chandel Navdeep S (2012). Physiological Roles of Mitochondrial Reactive Oxygen Species. Molecular Cell 48(2): 158167. doi: 10.1016/j.molcel.2012.09.025

27. Rhee SG, Bae YS, Lee S-R, Kwon J (2000). Hydrogen Peroxide: A Key Messenger That Modulates Protein Phosphorylation Through Cysteine Oxidation. Sci STKE 2000(53): pe1. doi: 10.1126/stke.2000.53.pe1

28. Masoro EJ (1998). Influence of caloric intake on aging and on the response to stressors. J Toxicol Environ Health B Crit Rev 1(3): 243 257. doi: 10.1080/10937409809524554

29. Schulz TJ, Zarse K, Voigt A, Urban N, Birringer M, Ristow M (2007) Glucose Restriction Extends Caenorhabditis elegans Life Span by Inducing Mitochondrial Respiration and Increasing Oxidative Stress. Cell Metab 6(4): 280-293. doi: 10.1016/j.cmet.2007.08.011

30. Ristow M, Schmeisser K (2014). Mitohormesis: Promoting Health and Lifespan by Increased Levels of Reactive Oxygen Species (ROS). Dose Response 12(2): 288-341. doi: 10.2203/dose-response.13035. Ristow

31. Calabrese EJ, Baldwin LA (2002). Defining hormesis. Hum Exp Toxicol 21(2): 91-97. doi: 10.1191/0960327102ht217oa 
32. Gray MW, Burger G, Lang BF (2001). The origin and early evolution of mitochondria. Genome Biol 2(6): reviews1018. PMID: 11423013

33. Rizzotti M (2009). The Earliest Anaerobic and Aerobic Life. In: Biological Science Fundamentals and Systematics - Vol. I.

34. Jiang $Y-Y$, Kong D-X, Qin T, Zhang H-Y (2010). How does oxygen rise drive evolution? Clues from oxygen-dependent biosynthesis of nuclear receptor ligands. Biochem Biophys Res Commun 391(2): 1158-1160. doi: 10.1016/j.bbrc.2009.11.041

35. Raymond J, Segrè D (2006). The Effect of Oxygen on Biochemical Networks and the Evolution of Complex Life. Science 311(5768): 1764. doi: 10.1126/science.1118439

36. Acquisti C, Kleffe J, Collins S (2006). Oxygen content of transmembrane proteins over macroevolutionary time scales. Nature 445(7123): 47. doi: 10.1038/nature05450

37. Cui $H$, Kong $Y$, Zhang $H$ (2012). Oxidative Stress, Mitochondrial Dysfunction, and Aging. J Signal Transduct 2012: 646354. doi: $10.1155 / 2012 / 646354$

38. Ighodaro OM, Akinloye OA (2017). First line defence antioxidantssuperoxide dismutase (SOD), catalase (CAT) and glutathione peroxidase (GPX): Their fundamental role in the entire antioxidant defence grid. Alexandria Journal of Medicine. doi: 10.1016/j.ajme.2017.09.001

39. Winterbourn CC (1995). Toxicity of iron and hydrogen peroxide: the Fenton reaction. Toxicol Lett 82-83: 969-974. doi: 10.1016/03784274(95)03532-X

40. Ahsan H, Ali A, Ali R (2003). Oxygen free radicals and systemic autoimmunity. Clin Exp Immunol 131(3): 398-404. doi: 10.1046/j.1365-2249.2003.02104.x

41. Sies H CE (1985). Oxidative stress: damage to intact cells and organs. Philos Trans R Soc Lond B Biol Sci 311(1152): 617. doi: 10.1098/rstb.1985.0168

42. Jena N (2012). DNA damage by reactive species: Mechanisms, mutation and repair. J Biosci 37(3): 14. doi: 10.1007/s12038-0129218-2

43. Araki K, Kusano H, Sasaki N, Tanaka R, Hatta T, Fukui K, Natsume T (2016). Redox Sensitivities of Global Cellular Cysteine Residues under Reductive and Oxidative Stress. J Proteome Res 15(8): 2548-2559. doi: 10.1021/acs.jproteome.6b00087

44. Cheeseman KH (1993). Mechanisms and effects of lipid peroxidation. Mol Aspects Med 14(3): 191-197. doi: 10.1016/00982997(93)90005-X

45. Kattoor AJ, Pothineni NVK, Palagiri D, Mehta JL (2017). Oxidative Stress in Atherosclerosis. Curr Atheroscler Rep 19(11): 42. doi: 10.1007/s11883-017-0678-6

46. Asmat U, Abad K, Ismail K (2016). Diabetes mellitus and oxidative stress-A concise review. Saudi Pharm J 24(5): 547-553. doi: 10.1016/j.jsps.2015.03.013

47. Srivastava KK, Kumar R (2015). Stress, Oxidative Injury and Disease. Indian J Clin Biochem 30(1): 3-10. doi: 10.1007/s12291-0140441-5

48. Giustarini D, Dalle-Donne I, Tsikas D, Rossi R (2009). Oxidative stress and human diseases: Origin, link, measurement, mechanisms, and biomarkers. Crit Rev Clin Lab Sci 46(5-6): 241-281. doi: 10.3109/10408360903142326

49. Espinosa-Diez C, Miguel V, Mennerich D, Kietzmann T, SánchezPérez P, Cadenas S, Lamas S (2015). Antioxidant responses and cellular adjustments to oxidative stress. Redox Biol 6: 183-197. doi: 10.1016/j.redox.2015.07.008
50. Fridovich I (1995). Superoxide Radical and Superoxide Dismutases. Annu Rev Biochem 64(1): 97-112. doi: 10.1146/annurev.bi.64.070195.000525

51. Sturtz LA, Diekert K, Jensen LT, Lill R, Culotta VC (2001). A Fraction of Yeast $\mathrm{Cu}, \mathrm{Zn}$-Superoxide Dismutase and Its Metallochaperone, CCS, Localize to the Intermembrane Space of Mitochondria: A physiological role for SOD1 in guarding against mitochondrial oxidative damage. J Biol Chem 276(41): 38084-38089. PMID: 11500508

52. Tsang CK, Liu Y, Thomas J, Zhang Y, Zheng XF (2014). Superoxide dismutase 1 acts as a nuclear transcription factor to regulate oxidative stress resistance. Nature Commun 5: 3446. doi 10.1038/ncomms4446

53. Karnati S, Lüers G, Pfreimer S, Baumgart-Vogt E (2013). Mammalian SOD2 is exclusively located in mitochondria and not present in peroxisomes. Histochem Cell Biol 140(2): 105-117. doi: 10.1007/s00418-013-1099-4

54. Kang L, Dai C, Lustig ME, Bonner JS, Mayes WH, Mokshagundam S, James FD, Thompson CS, Lin C-T, Perry CGR, Anderson EJ, Neufer PD, Wasserman DH, Powers AC (2014). Heterozygous SOD2 Deletion Impairs Glucose-Stimulated Insulin Secretion, but Not Insulin Action, in High-Fat-Fed Mice. Diabetes 63(11): 3699-3710. doi: 10.2337/db131845

55. Wang R, Yin C, Li X-X, Yang X-Z, Yang $Y$, Zhang $M-Y$, Wang $H-Y$, Zheng XFS (2016). Reduced SOD2 expression is associated with mortality of hepatocellular carcinoma patients in a mutant p53-dependent manner. Aging 8(6): 1184-1197. doi: 10.18632/aging.100967

56. Chang B, Yang H, Jiao Y, Wang K, Liu Z, Wu P, Li S, Wang A (2016). SOD2 deregulation enhances migration, invasion and has poor prognosis in salivary adenoid cystic carcinoma. Sci Rep 6: 25918. doi: 10.1038/srep25918

57. Qin Z, Reszka KJ, Fukai T, Weintraub NL (2008). Extracellular superoxide dismutase (ecSOD) in vascular biology: an update on exogenous gene transfer and endogenous regulators of ecSOD. Transl Res 151(2): 68-78. doi: 10.1016/j.trsl.2007.10.003

58. Lu Z, Xu X, Hu X, Zhu G, Zhang P, van Deel ED, French JP, Fassett JT, Oury TD, Bache RJ, Chen Y (2008). Extracellular Superoxide Dismutase Deficiency Exacerbates Pressure Overload-Induced Left Ventricular Hypertrophy and Dysfunction. Hypertension 51(1): 19-25. doi: 10.1161/HYPERTENSIONAHA.107.098186

59. Kliment CR, Tobolewski JM, Manni ML, Tan RJ, Enghild J, Oury TD (2008). Extracellular Superoxide Dismutase Protects Against Matrix Degradation of Heparan Sulfate in the Lung. Antioxid Redox Signal 10(2): 261-268. doi: 10.1089/ars.2007.1906

60. Chelikani P, Fita I, Loewen PC (2004). Diversity of structures and properties among catalases. Cell Mol Life Sci 61(2): 192-208. doi: 10.1007/s00018-003-3206-5

61. Zamocky M, Furtmüller PG, Obinger C (2008). Evolution of Catalases from Bacteria to Humans. Antioxid Redox Signal 10(9): 15271548. doi: 10.1089/ars.2008.2046

62. Birben E, Sahiner UM, Sackesen C, Erzurum S, Kalayci O (2012). Oxidative Stress and Antioxidant Defense. World Allergy Organ J 5(1): 9-19. doi: 10.1097/WOX.0b013e3182439613

63. Tabet F, Touyz RM (2007). Chapter 30 - Reactive Oxygen Species, Oxidative Stress, and Vascular Biology in Hypertension A2 - Lip, Gregory Y.H. In: Hall JE, editor Comprehensive Hypertension. Mosby, Philadelphia; pp 337-347.

64. Yang Y CJ, Singhal SS, Saini M, Pandya U, Awasthi S, Awasthi YC. (2001). Role of Glutathione S-Transferases in Protection against Lipid Peroxidation. Overexpression of HGSTA2-2 in K562 cells protects against hydrogen peroxide-induced apoptosis and inhibits jnk and 
caspase 3 activation. J Biol Chem 276(22): 19220-19230. doi: 10.1074/jbc.M100551200

65. Gill SS, Tuteja N (2010). Reactive oxygen species and antioxidant machinery in abiotic stress tolerance in crop plants. Plant Physiol Biochem 48(12): 909-930. doi: 10.1016/j.plaphy.2010.08.016

66. Castilla-Cortázar Larrea I, Muñoz U (2012). Protection Against Oxidative Stress and "IGF-I Deficiency Conditions". IntechOpen: 28. doi: $10.5772 / 51047$

67. Muller FL, Lustgarten MS, Jang $Y$, Richardson A, Van Remmen $H$ (2007). Trends in oxidative aging theories. Free Radical Biology and Medicine 43(4): 477-503. doi: 10.1016/j.freeradbiomed.2007.03.034

68. Brigelius-Flohé R (1999). Tissue-specific functions of individual glutathione peroxidases. Free Radic Biol Med 27(9): 951-965. doi: 10.1016/S0891-5849(99)00173-2

69. Rocha S, Gomes D, Lima M, Bronze-da-Rocha E, Santos-Silva A (2015). Peroxiredoxin 2, glutathione peroxidase, and catalase in the cytosol and membrane of erythrocytes under $\mathrm{H} 2 \mathrm{O} 2$-induced oxidative stress. Free Radic Res 49(8): 990-1003. doi: 10.3109/10715762.2015.1028402

70. Mustacich D, Powis G (2000). Thioredoxin reductase. Biochem J 346(Pt 1): 1-8. doi: 10.1042/bj3460001

71. Bindoli A, Rigobello MP, Scutari G, Gabbiani C, Casini A, Messori L (2009). Thioredoxin reductase: $A$ target for gold compounds acting as potential anticancer drugs. Coordination Chemistry Reviews 253(1112): 1692-1707. doi: 10.1016/j.ccr.2009.02.026

72. Lee S, Kim SM, Lee RT (2013). Thioredoxin and Thioredoxin Target Proteins: From Molecular Mechanisms to Functional Significance. Antioxid Redox Signal 18(10): 1165-1207. doi: 10.1089/ars.2011.4322

73. Hojo Y, Saito Y, Tanimoto T, Hoefen RJ, Baines CP, Yamamoto K, Haendeler J, Asmis R, Berk BC (2002). Fluid shear stress attenuates hydrogen peroxide-induced c-Jun $\mathrm{NH} 2$-terminal kinase activation via a glutathione reductase-mediated mechanism. Circ Res 91(8): 712. doi: 10.1161/01.RES.0000037981.97541.25

74. Hrabe JE, O'Leary BR, Fath MA, Rodman SN, Button AM, Domann FE, Spitz DR, Mezhir JJ (2015). Disruption of thioredoxin metabolism enhances the toxicity of transforming growth factor $\beta$-activated kinase 1 (TAK1) inhibition in KRAS-mutated colon cancer cells. Redox Biol 5: 319-327. doi: 10.1016/j.redox.2015.06.004

75. Benhar M (2018). Roles of mammalian glutathione peroxidase and thioredoxin reductase enzymes in the cellular response to nitrosative stress. Free Radic Biol Med doi: 10.1016/j.freeradbiomed.2018.01.028

76. Khan AUH, Allende-Vega N, Gitenay D, Garaude J, Vo D-N, Belkhala $S$, Gerbal-Chaloin S, Gondeau C, Daujat-Chavanieu M, Delettre C, Orecchioni S, Talarico G, Bertolini F, Anel A, Cuezva JM, Enriquez JA, Cartron G, Lecellier C-H, Hernandez J, Villalba M (2018). Mitochondrial Complex I activity signals antioxidant response through ERK5. Sci Rep 8(1): 7420. doi: 10.1038/s41598-018-23884-4

77. Gongora MC, Lob HE, Landmesser U, Guzik TJ, Martin WD, Ozumi K, Wall SM, Wilson DS, Murthy N, Gravanis M, Fukai T, Harrison DG (2008). Loss of Extracellular Superoxide Dismutase Leads to Acute Lung Damage in the Presence of Ambient Air : A Potential Mechanism Underlying Adult Respiratory Distress Syndrome. Am J Pathol 173(4): 915-926. doi: 10.2353/ajpath.2008.080119

78. Mira E, Carmona-Rodríguez L, Pérez-Villamil B, Casas J, FernándezAceñero MJ, Martínez-Rey D, Martín-González P, Heras-Murillo I, PazCabezas M, Tardáguila M, Oury TD, Martín-Puig S, Lacalle RA, Fabriás G, Díaz-Rubio E, Mañes S (2018). SOD3 improves the tumor response to chemotherapy by stabilizing endothelial HIF-2 $\alpha$. Nature Commun 9(1): 575. doi: 10.1038/s41467-018-03079-1
79. Sau D, De Biasi S, Vitellaro-Zuccarello L, Riso P, Guarnieri S, Porrini $M$, Simeoni S, Crippa V, Onesto E, Palazzolo I, Rusmini P, Bolzoni E, Bendotti C, Poletti A (2007). Mutation of SOD1 in ALS: a gain of a loss of function. Hum Mol Genet 16(13): 1604-1618. doi: 10.1093/hmg/ddm110

80. Glorieux C, Dejeans N, Sid B, Beck R, Calderon PB, Verrax J (2011). Catalase overexpression in mammary cancer cells leads to a less aggressive phenotype and an altered response to chemotherapy. Biochem Pharmacol 82(10): 1384-1390. doi: 10.1016/j.bcp.2011.06.007

81. Góth L (2008). Catalase Deficiency and Type 2 Diabetes. Diabetes Care 31(12): e93. doi: 10.2337/dc08-1607

82. Yao C, Behring JB, Shao D, Sverdlov AL, Whelan SA, Elezaby A, Yin $X$, Siwik DA, Seta F, Costello CE, Cohen RA, Matsui R, Colucci WS, McComb ME, Bachschmid MM (2015). Overexpression of Catalase Diminishes Oxidative Cysteine Modifications of Cardiac Proteins. PLOS ONE 10(12): e0144025. doi: 10.1371/journal.pone.0144025

83. Rezvani HR, Mazurier F, Cario-André M, pain C, Ged C, Taïeb A, de Verneuil $H$ (2006). Protective effects of catalase overexpression on UVB-induced apoptosis in normal human keratinocytes. J Biol Chem 281(26):17999-8007. doi: 10.1074/jbc.M600536200

84. Gurgul E, Lortz S, Tiedge M, Jörns A, Lenzen S (2004). Mitochondrial Catalase Overexpression Protects Insulin-Producing Cells Against Toxicity of Reactive Oxygen Species and Proinflammatory Cytokines. Diabetes 53(9): 2271. doi: 10.2337/diabetes.53.9.2271

85. Lee DH, Son DJ, Park MH, Yoon DY, Han SB, Hong JT (2016). Glutathione peroxidase 1 deficiency attenuates concanavalin $A$-induced hepatic injury by modulation of T-cell activation. Cell Death Dis 7(4): e2208. doi: 10.1038/cddis.2016.95

86. Martinus RD, Garth GP, Webster TL, Cartwright P, Naylor DJ, Høj $P B$, Hoogenraad NJ (1996). Selective Induction of Mitochondrial Chaperones in Response to Loss of the Mitochondrial Genome. Eur J Biochem 240(1): 98-103. doi: 10.1111/j.1432-1033.1996.0098h.x

87. Zhao Q, Wang J, Levichkin IV, Stasinopoulos S, Ryan MT, Hoogenraad NJ (2002). A mitochondrial specific stress response in mammalian cells. EMBO J 21(17): 4411. doi: 10.1093/emboj/cdf445

88. MacKenzie JA, Mark Payne R (2007). Mitochondrial Protein Import and Human Health and Disease. Biochim Biophys Acta 1772(5): 509523. doi: 10.1016/j.bbadis.2006.12.002

89. Shigenaga MK, Hagen TM, Ames BN (1994). Oxidative damage and mitochondrial decay in aging. Proc Natl Acad Sci U S A 91(23): 1077110778. doi: 10.1073/pnas.91.23.10771

90. Chacinska A, Koehler CM, Milenkovic D, Lithgow T, Pfanner N (2009). Importing Mitochondrial Proteins: Machineries and Mechanisms. Cell 138(4): 628-644. doi: 10.1016/j.cell.2009.08.005

91. Melber A, Haynes CM (2018). UPRmt regulation and output: a stress response mediated by mitochondrial-nuclear communication. Cell Res 28: 281. doi: 10.1038/cr.2018.16

92. Fischer M, Riemer J (2013). The mitochondrial disulfide relay system: roles in oxidative protein folding and beyond. Int J Cell Biol 2013: 742923. doi: $10.1155 / 2013 / 742923$

93. Yoneda T, Benedetti C, Urano F, Clark SG, Harding HP, Ron D (2004). Compartment-specific perturbation of protein handling activates genes encoding mitochondrial chaperones. J Cell Sci 117(18): 4055. doi: $10.1242 /$ jcs. 01275

94. Haynes CM, Yang Y, Blais SP, Neubert TA, Ron D (2010). The Matrix Peptide Exporter HAF-1 Signals a Mitochondrial UPR by Activating the Transcription Factor ZC376.7 in C. elegans. Mol Cell 37(4): 529-540. doi: 10.1016/j.molcel.2010.01.015

95. Merkwirth C, Jovaisaite V, Durieux J, Matilainen O, Jordan Sabine D, Quiros Pedro M, Steffen Kristan K, Williams Evan G, Mouchiroud L, 
Tronnes Sarah U, Murillo V, Wolff Suzanne C, Shaw Reuben J, Auwerx J, Dillin A (2016). Two Conserved Histone Demethylases Regulate Mitochondrial Stress-Induced Longevity. Cell 165(5): 1209-1223. doi: 10.1016/j.cell.2016.04.012

96. Nargund AM, Pellegrino MW, Fiorese CJ, Baker BM, Haynes CM (2012). Mitochondrial Import Efficiency of ATFS-1 Regulates Mitochondrial UPR Activation. Science 337(6094):587-90. doi: 10.1126/science. 1223560

97. Nargund Amrita M, Fiorese Christopher J, Pellegrino Mark W, Deng $P$, Haynes Cole M (2015). Mitochondrial and Nuclear Accumulation of the Transcription Factor ATFS-1 Promotes OXPHOS Recovery during the UPRmt. Mol Cell 58(1): 123-133. doi: 10.1016/j.molcel.2015.02.008

98. Oks O, Lewin S, Goncalves IL, Sapir A (2018). The UPRmt Protects Caenorhabditis elegans from Mitochondrial Dysfunction by Upregulating Specific Enzymes of the Mevalonate Pathway. Genetics 209(2): 457. doi: 10.1534/genetics.118.300863

99. Holstein SA, Hohl RJ (2004). Isoprenoids: Remarkable diversity of form and function. Lipids 39(4): 293-309. doi:10.1007/s11745-0041233-3

100. Hoogenraad N (2017). A brief history of the discovery of the mitochondrial unfolded protein response in mammalian cells. J Bioenerg Biomembr 49(4): 293-295. doi: 10.1007/s10863-017-9703-2

101. Aldridge JE, Horibe T, Hoogenraad NJ (2007). Discovery of Genes Activated by the Mitochondrial Unfolded Protein Response (mtUPR) and Cognate Promoter Elements. PLOS ONE 2(9): e874. doi: 10.1371/journal.pone.0000874

102. Horibe T, Hoogenraad NJ (2007). The Chop Gene Contains an Element for the Positive Regulation of the Mitochondrial Unfolded Protein Response. PLOS ONE 2(9): e835. doi: 10.1371/journal.pone.0000835

103. Münch C (2018). The different axes of the mammalian mitochondrial unfolded protein response. BMC Biology 16: 81. doi: 10.1186/s12915-018-0548-x

104. Radke S, Chander H, Schäfer P, Meiss G, Krüger R, Schulz JB, Germain D (2008). Mitochondrial Protein Quality Control by the Proteasome Involves Ubiquitination and the Protease Omi. J Biol Chem 283(19): 12681-12685. doi: 10.1074/jbc.C800036200

105. Campbell RA, Bhat-Nakshatri P, Patel NM, Constantinidou D, Ali S, Nakshatri H (2001). Phosphatidylinositol 3-Kinase/AKT-mediated Activation of Estrogen Receptor $\alpha$ : A new model for anti-estrogen resistance. J Biol Chem 276(13): 9817-9824. doi: 10.1074/jbc.M010840200

106. Sun M, Paciga JE, Feldman RI, Yuan Z-q, Coppola D, Lu YY, Shelley SA, Nicosia SV, Cheng JQ (2001). Phosphatidylinositol-3-OH Kinase (PI3K)/AKT2, Activated in Breast Cancer, Regulates and Is Induced by Estrogen Receptor $\alpha(E R \alpha)$ via Interaction between ER $\alpha$ and PI3K. Cancer Res 61(16): 5985-5991. PMID: 11507039

107. Papa L, Germain D (2011). Estrogen receptor mediates a distinct mitochondrial unfolded protein response. J Cell Sci 124(9): 1396. doi: $10.1242 /$ jcs.078220

108. Baker BM, Nargund AM, Sun T, Haynes CM (2012). Protective Coupling of Mitochondrial Function and Protein Synthesis via the elF2 $\alpha$ Kinase GCN-2. PLoS Genet 8(6): e1002760. doi: 10.1371/journal.pgen.1002760

109. Pakos-Zebrucka K, Koryga I, Mnich K, Ljujic M, Samali A, Gorman AM (2016). The integrated stress response. EMBO Rep 17(10): 13741395. doi: 10.15252/embr.201642195

110. Teske BF, Fusakio ME, Zhou D, Shan J, McClintick JN, Kilberg MS, Wek RC, Luo K (2013). CHOP induces activating transcription factor 5
(ATF5) to trigger apoptosis in response to perturbations in protein homeostasis. Mol Biol Cell 24(15): 2477-2490. doi: 10.1091/mbc.e1301-0067

111. Fiorese Christopher J, Schulz Anna M, Lin Y-F, Rosin N, Pellegrino Mark W, Haynes Cole M (2016). The Transcription Factor ATF5 Mediates a Mammalian Mitochondrial UPR. Curr Biol 26(15): 2037-2043. doi: 10.1016/j.cub.2016.06.002

112. Kulalert W, Sadeeshkumar H, Zhang YK, Schroeder FC, Kim DH (2017). Molecular Determinants of the Regulation of Development and Metabolism by Neuronal elF2 $\alpha$ Phosphorylation in Caenorhabditis elegans. Genetics 206(1): 251-263. doi: 10.1534/genetics.117.200568

113. Tyynismaa $H$, Mjosund KP, Wanrooij S, Lappalainen I, Ylikallio E, Jalanko A, Spelbrink JN, Paetau A, Suomalainen A (2005). Mutant mitochondrial helicase Twinkle causes multiple mtDNA deletions and a late-onset mitochondrial disease in mice. Proc Natl Acad Sci U S A 102(49): 17687-17692. doi: 10.1073/pnas.0505551102

114. Tyynismaa H, Carroll CJ, Raimundo N, Ahola-Erkkilä S, Wenz T, Ruhanen H, Guse K, Hemminki A, Peltola-Mjøsund KE, Tulkki V, Orešič M, Moraes CT, Pietiläinen K, Hovatta I, Suomalainen A (2010). Mitochondrial myopathy induces a starvation-like response. Hum Mol Genet 19(20): 3948-3958. doi: 10.1093/hmg/ddq310

115. Quirós PM, Prado MA, Zamboni N, D’Amico D, Williams RW, Finley D, Gygi SP, Auwerx J (2017). Multi-omics analysis identifies ATF4 as a key regulator of the mitochondrial stress response in mammals. J Cell Biol 216(7):2027-2045. doi: 10.1083/jcb.201702058

116. Celardo I, Costa AC, Lehmann S, Jones C, Wood N, Mencacci NE, Mallucci GR, Loh SHY, Martins LM (2016). Mitofusin-mediated ER stress triggers neurodegeneration in pink1/parkin models of Parkinson's disease. Cell Death Dis 7(6): e2271. doi: 10.1038/cddis.2016.173

117. Kozutsumi Y, Segal M, Normington K, Gething M-J, Sambrook J (1988). The presence of malfolded proteins in the endoplasmic reticulum signals the induction of glucose-regulated proteins. Nature 332(6163): 462. doi: 10.1038/332462a0

118. Ma Y, Hendershot LM (2001). The Unfolding Tale of the Unfolded Protein Response. Cell 107(7): 827-830. doi: 10.1016/S00928674(01)00623-7

119. Karam R, Lou C-H, Kroeger $\mathrm{H}$, Huang L, Lin JH, Wilkinson MF (2015). The unfolded protein response is shaped by the NMD pathway. EMBO Rep 16(5): 599-609. doi: 10.15252/embr.201439696

120. Tang C-HA, Chang S, Paton AW, Paton JC, Gabrilovich DI, Ploegh $\mathrm{HL}$, Del Valle JR, Hu C-CA (2018). Phosphorylation of IRE1 at S729 regulates RIDD in $B$ cells and antibody production after immunization. J Cell Biol 217(5): 1739-1755. doi: 10.1083/jcb.201709137

121. Ma Y, Shimizu Y, Mann MJ, Jin Y, Hendershot LM (2010). Plasma cell differentiation initiates a limited ER stress response by specifically suppressing the PERK-dependent branch of the unfolded protein response. Cell Stress Chaperones 15(3): 281-293. doi: 10.1007/s12192-009-0142-9

122. Yoshida H, Matsui T, Yamamoto A, Okada T, Mori K (2001). XBP1 mRNA Is Induced by ATF6 and Spliced by IRE1 in Response to ER Stress to Produce a Highly Active Transcription Factor. Cell 107(7): 881-891. doi: 10.1016/S0092-8674(01)00611-0

123. Tsuru A, Imai Y, Saito M, Kohno K (2016). Novel mechanism of enhancing IRE1 $\alpha$-XBP1 signalling via the PERK-ATF4 pathway. Sci Rep 6(2016): 24217. doi: 10.1038/srep24217

124. Zong W-X, Li C, Hatzivassiliou G, Lindsten T, Yu Q-C, Yuan J, Thompson CB (2003). Bax and Bak can localize to the endoplasmic reticulum to initiate apoptosis. J Cell Biol 162(1): 59. doi: 10.1083/jcb.200302084 
125. Murley A, Nunnari J (2016). The emerging network of mitochondria-organelle contacts. Mol Cell 61(5): 648-653. doi: 10.1016/j.molcel.2016.01.031

126. Rizzuto R, Pinton P, Carrington W, Fay FS, Fogarty KE, Lifshitz LM, Tuft RA, Pozzan T (1998). Close Contacts with the Endoplasmic Reticulum as Determinants of Mitochondrial Ca2+ Responses. Science 280(5370): 1763. doi: 10.1126/science.280.5370.1763

127. Rowland AA, Voeltz GK (2012). Endoplasmic reticulummitochondria contacts: function of the junction. Nat Rev Mol Cell Biol 13(10): 607-625. doi: 10.1038/nrm3440

128. Lim JH, Lee HJ, Ho Jung M, Song J (2009). Coupling mitochondrial dysfunction to endoplasmic reticulum stress response: A molecular mechanism leading to hepatic insulin resistance. Cell Signal 21(1): 169-177. doi: 10.1016/j.cellsig.2008.10.004

129. Muñoz JP, Ivanova S, Sánchez-Wandelmer J, Martínez-Cristóbal $P$, Noguera E, Sancho A, Díaz-Ramos A, Hernández-Alvarez MI, Sebastián D, Mauvezin C, Palacín M, Zorzano A (2013). Mfn2 modulates the UPR and mitochondrial function via repression of PERK. EMBO J 32(17): 2348-2361. doi: 10.1038/emboj.2013.168

130. Hori O, Ichinoda F, Tamatani T, Yamaguchi A, Sato N, Ozawa K, Kitao Y, Miyazaki M, Harding HP, Ron D, Tohyama M, M Stern D, Ogawa $S$ (2002). Transmission of cell stress from endoplasmic reticulum to mitochondria. J Cell Biol 157(7): 1151. doi: 10.1083/jcb.200108103

131. Manfredi G, Kawamata H (2016). Mitochondria and endoplasmic reticulum crosstalk in amyotrophic lateral sclerosis. Neurobiol Dis 90(2016): 35-42. doi: 10.1016/j.nbd.2015.08.004

132. Arsenovic PT, Maldonado AT, Colleluori VD, Bloss TA (2012). Depletion of the C. elegans NAC Engages the Unfolded Protein Response, Resulting in Increased Chaperone Expression and Apoptosis. PLOS ONE 7(9): e44038. doi: 10.1371/journal.pone.0044038

133. Vabulas RM, Raychaudhuri S, Hayer-Hartl M, Hartl FU (2010). Protein Folding in the Cytoplasm and the Heat Shock Response. Cold Spring Harb Perspect Biol 2(12): a004390. doi: 10.1101/cshperspect.a004390

134. Hesterkamp T, Bukau B (1998). Role of the DnaK and HscA homologs of Hsp70 chaperones in protein folding in E.coli. EMBO J 17(16): 4818-4828. doi: 10.1093/emboj/17.16.4818

135. Kramer G, Boehringer D, Ban N, Bukau B (2009). The ribosome as a platform for co-translational processing, folding and targeting of newly synthesized proteins. Nat Struct Mol Biol 16(6): 589-597. doi: 10.1038/nsmb.1614

136. Leitner A, Joachimiak LA, Bracher A, Mönkemeyer L, Walzthoeni $T$, Chen B, Pechmann S, Holmes S, Cong Y, Ma B, Ludtke S, Chiu W, Hartl FU, Aebersold R, Frydman J (2012). The molecular architecture of the eukaryotic chaperonin TRiC/CCT. Structure 20(5): 814-825. doi: 10.1016/j.str.2012.03.007

137. Joachimiak LA, Walzthoeni T, Liu C, Aebersold R, Frydman J (2014). The structural basis of substrate recognition by the eukaryotic chaperonin TRiC/CCT. Cell 159(5): 1042-1055. doi: 10.1016/j.cell.2014.10.042

138. Pereira JH, McAndrew RP, Sergeeva OA, Ralston CY, King JA, Adams PD (2017). Structure of the human TRiC/CCT Subunit 5 associated with hereditary sensory neuropathy. Sci Rep 7(1): 3673. doi: 10.1038/s41598-017-03825-3

139. Roh S-H, Kasembeli M, Bakthavatsalam D, Chiu W, Tweardy DJ (2015). Contribution of the Type II Chaperonin, TRiC/CCT, to Oncogenesis. Int J Mol Sci 16(11): 26706-26720. doi: 10.3390/ijms161125975

140. Melkani Girish C, Bhide S, Han A, Vyas J, Livelo C, Bodmer R, Bernstein Sanford I (2017). TRiC/CCT chaperonins are essential for maintaining myofibril organization, cardiac physiological rhythm, and lifespan. FEBS Lett 591(21): 3447-3458. doi: 10.1002/1873 3468.12860

141. Khabirova E, Moloney A, Marciniak SJ, Williams J, Lomas DA, Oliver SG, Favrin G, Sattelle DB, Crowther DC (2014). The TRiC/CCT Chaperone Is Implicated in Alzheimer's Disease Based on Patient GWAS and an RNAi Screen in A $\beta$-Expressing Caenorhabditis elegans. PLOS ONE 9(7): e102985. doi: 10.1371/journal.pone.0102985

142. Qiao A, Jin X, Pang J, Moskophidis D, Mivechi NF (2017). The transcriptional regulator of the chaperone response HSF1 controls hepatic bioenergetics and protein homeostasis. J Cell Biol 216(3): 723741. doi: $10.1083 /$ jcb.201607091

143. Labbadia J, Brielmann RM, Neto MF, Lin YF, Haynes CM, Morimoto RI (2017). Mitochondrial stress restores the heat shock response and prevents proteostasis collapse during aging. Cell Rep 21(6): 14811494. doi: 10.1016/j.celrep.2017.10.038

144. Gomes LC, Di Benedetto G, Scorrano L (2011). During autophagy mitochondria elongate, are spared from degradation and sustain cell viability. Nat Cell Biol 13(5): 589-598. doi: 10.1038/ncb2220

145. Heo J-W, No M-H, Park D-H, Kang J-H, Seo DY, Han J, Neufer PD, Kwak H-B (2017). Effects of exercise on obesity-induced mitochondrial dysfunction in skeletal muscle. Korean J Physiol Pharmacol 21(6) 567-577. doi: 10.4196/kjpp.2017.21.6.567

146. Rovira-Llopis S, Bañuls C, Diaz-Morales N, Hernandez-Mijares A, Rocha M, Victor VM (2017). Mitochondrial dynamics in type 2 diabetes: Pathophysiological implications. Redox Biol 11: 637-645. doi: 10.1016/j.redox.2017.01.013

147. Knowlton AA, Liu TT (2015). Mitochondrial Dynamics and Heart Failure. Compr Physiol 6(1): 507-526. doi: 10.1002/cphy.c150022

148. Wang X, Su B, Zheng L, Perry G, Smith MA, Zhu X (2009). The Role of Abnormal Mitochondrial Dynamics in the Pathogenesis of Alzheimer's Disease. J Neurochem 109(Suppl 1): 153-159. doi: 10.1111/j.1471-4159.2009.05867.x

149. Cai Q, Tammineni $P$ (2016). Alterations in Mitochondrial Quality Control in Alzheimer's Disease. Front Cell Neurosci 10: 24. doi: 10.3389/fncel.2016.00024

150. Selfridge JE, Lezi E, Lu J, Swerdlow RH (2013). Role of Mitochondrial Homeostasis and Dynamics in Alzheimer's Disease. Neurobiol Dis 51: 3-12. doi: 10.1016/j.nbd.2011.12.057

151. Zhu X, Perry G, Smith MA, Wang X (2013). Abnormal Mitochondrial Dynamics in the Pathogenesis of Alzheimer's Disease. J Alzheimers Dis 33(0 1): S253-S262. doi: 10.3233/jad-2012-129005

152. Bose A, Beal MF (2016). Mitochondrial dysfunction in Parkinson's disease. J Neurochem 139(S1): 216-231. doi: 10.1111/jnc.13731

153. Luo Y, Hoffer A, Hoffer B, Qi X (2015). Mitochondria: A Therapeutic Target for Parkinson's Disease? Int J Mol Sci 16(9): 20704-20730. doi: 10.3390/ijms160920704

154. Gaziev Al, Abdullaev S, Podlutsky A (2014). Mitochondrial function and mitochondrial DNA maintenance with advancing age. Biogerontology 15(5): 417-438. doi: 10.1007/s10522-014-9515-2

155. Seo AY, Joseph A-M, Dutta D, Hwang JCY, Aris JP, Leeuwenburgh $C$ (2010). New insights into the role of mitochondria in aging: mitochondrial dynamics and more. J Cell Sci 123(15): 2533-2542. doi: 10.1242/jcs.070490

156. Mansfield KD, Guzy RD, Pan Y, Young RM, Cash TP, Schumacker PT, Simon MC (2005). Mitochondrial dysfunction resulting from loss of cytochrome $\mathrm{c}$ impairs cellular oxygen sensing and hypoxic HIF- $\alpha$ activation. Cell Metab 1(6): 393-399. doi: 10.1016/j.cmet.2005.05.003 
157. Crompton M (1999). The mitochondrial permeability transition pore and its role in cell death. Biochem J 341(Pt 2): 233-249. doi 10.1042/0264-6021:3410233

158. Abeliovich H, Zarei M, Rigbolt KTG, Youle RJ, Dengjel J (2013) Involvement of mitochondrial dynamics in the segregation of mitochondrial matrix proteins during stationary phase mitophagy. Nature Commun 4: 2789. doi: 10.1038/ncomms3789

159. Mao K, Wang K, Liu X, Klionsky DJ (2013). The scaffold protein Atg11 recruits fission machinery to drive selective mitochondria degradation by autophagy. Dev Cell 26(1): 9-18. doi: 10.1016/j.devcel.2013.05.024

160. Ikeda Y, Shirakabe A, Maejima Y, Zhai P, Sciarretta S, Toli J, Nomura M, Mihara K, Egashira K, Ohishi M, Abdellatif M, Sadoshima (2015). Endogenous Drp1 mediates mitochondrial autophagy and protects the heart against energy stress. Circ Res 116(2): 264. doi: 10.1161/CIRCRESAHA.116.303356

161. Yamashita S-i, Jin X, Furukawa K, Hamasaki M, Nezu A, Otera $H$ Saigusa T, Yoshimori T, Sakai Y, Mihara K, Kanki T (2016). Mitochondrial division occurs concurrently with autophagosome formation but independently of Drp1 during mitophagy. J Cell Biol 215(5): 649-665. doi: $10.1083 /$ jcb.201605093

162. Rambold AS, Kostelecky B, Elia N, Lippincott-Schwartz J (2011) Tubular network formation protects mitochondria from autophagosomal degradation during nutrient starvation. Proc Natl Acad Sci U S A 108(25): 10190-10195. doi: 10.1073/pnas.1107402108

163. Twig G, Elorza A, Molina AJA, Mohamed H, Wikstrom JD, Walzer G, Stiles L, Haigh SE, Katz S, Las G, Alroy J, Wu M, Py BF, Yuan J, Deeney JT, Corkey BE, Shirihai OS (2008). Fission and selective fusion govern mitochondrial segregation and elimination by autophagy. EMBO J 27(2): 433-446. doi: 10.1038/sj.emboj.7601963

164. Basit F, van Oppen LMPE, Schöckel L, Bossenbroek HM, van Emstde Vries SE, Hermeling JCW, Grefte S, Kopitz C, Heroult M, Hgm Willems P, Koopman WJH (2017). Mitochondrial complex I inhibition triggers a mitophagy-dependent ROS increase leading to necroptosis and ferroptosis in melanoma cells. Cell Death Dis 8: e2716. doi: 10.1038/cddis.2017.133

165. Smirnova E, Griparic L, Shurland D-L, van der Bliek AM (2001). Dynamin-related Protein Drp1 Is Required for Mitochondrial Division in Mammalian Cells. Mol Biol Cell 12(8): 2245-2256. doi: $10.1091 / \mathrm{mbc} .12 .8 .2245$

166. Otera $\mathrm{H}$, Ishihara N, Mihara $\mathrm{K}$ (2013). New insights into the function and regulation of mitochondrial fission. Biochim Biophys Acta 1833(5): 1256-1268. doi: 10.1016/j.bbamcr.2013.02.002

167. Barsoum MJ, Yuan H, Gerencser AA, Liot G, Kushnareva Y, Gräber $S$, Kovacs I, Lee WD, Waggoner J, Cui J, White AD, Bossy B, Martinou JC, Youle RJ, Lipton SA, Ellisman MH, Perkins GA, Bossy-Wetzel E (2006). Nitric oxide-induced mitochondrial fission is regulated by dynamin-related GTPases in neurons. EMBO J 25(16): 3900-3911. doi: 10.1038/sj.emboj.7601253

168. Burman JL, Pickles S, Wang C, Sekine S, Vargas JNS, Zhang Z, Youle AM, Nezich CL, Wu X, Hammer JA, Youle RJ (2017). Mitochondrial fission facilitates the selective mitophagy of protein aggregates. $\mathbf{J}$ Cell Biol 216(10):3231-3247. doi: 10.1083/jcb.201612106

169. McWilliams TG, Muqit MMK (2017). PINK1 and Parkin: emerging themes in mitochondrial homeostasis. Curr Opin Cell Biol 45: 83-91. doi: 10.1016/j.ceb.2017.03.013

170. Wai T, Saita S, Nolte H, Müller S, König T, Richter-Dennerlein R, Sprenger HG, Madrenas J, Mühlmeister M, Brandt U, Krüger M, Langer $T$ (2016). The membrane scaffold SLP2 anchors a proteolytic hub in mitochondria containing PARL and the i-AAA protease YME1L. EMBO Rep 17(12): 1844-1856. doi: 10.15252/embr.201642698
171. Gegg ME, Cooper JM, Chau K-Y, Rojo M, Schapira AHV, Taanman $\mathrm{J}-\mathrm{W}$ (2010). Mitofusin 1 and mitofusin 2 are ubiquitinated in a PINK1/parkin-dependent manner upon induction of mitophagy. Hum Mol Genet 19(24): 4861-4870. doi: $10.1093 / \mathrm{hmg} / \mathrm{ddq} 419$

172. Gegg ME, Schapira AHV (2011). PINK1-parkin-dependent mitophagy involves ubiquitination of mitofusins 1 and 2: Implications for Parkinson disease pathogenesis. Autophagy 7(2): 243-245. doi: 10.4161/auto.7.2.14332

173. Cha-Molstad H, Yu JE, Feng Z, Lee SH, Kim JG, Yang P, Han B, Sung KW, Yoo YD, Hwang J, McGuire T, Shim SM, Song HD, Ganipisetti S, Wang N, Jang JM, Lee MJ, Kim SJ, Lee KH, Hong JT, Ciechanover A Mook-Jung I, Kim KP, Xie X-Q, Kwon YT, Kim BY (2017). p62/SQSTM1/Sequestosome-1 is an N-recognin of the $\mathrm{N}$-end rule pathway which modulates autophagosome biogenesis. Nat Commun 8(1): 102. doi: 10.1038/s41467-017-00085-7

174. P. Narendra D, Kane L, Hauser D, M Fearnley I, J Youle R (2010). p62/SQSTM1 is required for Parkin-induced mitochondrial clustering but not mitophagy; VDAC1 is dispensable for both. Autophagy 6(8): 1090-1106. doi: 10.4161/auto.6.8.13426

175. Patten DA, Wong J, Khacho M, Soubannier V, Mailloux RJ, PilonLarose K, MacLaurin JG, Park DS, McBride HM, Trinkle-Mulcahy L, Harper M-E, Germain M, Slack RS (2014). OPA1-dependent cristae modulation is essential for cellular adaptation to metabolic demand. EMBO J 33(22): 2676-2691. doi: 10.15252/embj.201488349

176. Song Z, Ghochani M, McCaffery JM, Frey TG, Chan DC (2009). Mitofusins and OPA1 Mediate Sequential Steps in Mitochondrial Membrane Fusion. Mol Biol Cell 20(15): 3525-3532. doi: 10.1091/mbc.E09-03-0252

177. Delettre C, Griffoin J-M, Kaplan J, Dollfus H, Lorenz B, Faivre L, Lenaers $G$, Belenguer $P$, Hamel CP (2001). Mutation spectrum and splicing variants in the OPA1 gene. Hum Genet 109(6): 584-591. doi: 10.1007/s00439-001-0633-y

178. Griparic L, Kanazawa T, van der Bliek AM (2007). Regulation of the mitochondrial dynamin-like protein Opa1 by proteolytic cleavage. J Cell Biol 178(5): 757-764. doi: 10.1083/jcb.200704112

179. Song Z, Chen H, Fiket M, Alexander C, Chan DC (2007). OPA1 processing controls mitochondrial fusion and is regulated by mRNA splicing, membrane potential, and Yme1L. J Cell Biol 178(5): 749-755. doi: $10.1083 /$ jcb. 200704110

180. MacVicar TDB, Lane JD (2014). Impaired OMA1-dependent cleavage of OPA1 and reduced DRP1 fission activity combine to prevent mitophagy in cells that are dependent on oxidative phosphorylation. J Cell Sci 127(10): 2313-2325. doi: 10.1242/jcs.144337

181. Kanki T (2010). Nix: A receptor protein for mitophagy in mammals. Autophagy 6(3): 433-435. doi: 10.4161/auto.6.3.11420

182. Padman BS, Nguyen TN, Lazarou M (2017). Autophagosome formation and cargo sequestration in the absence of LC3/GABARAPs. Autophagy 13(4): 772-774. doi: 10.1080/15548627.2017.1281492

183. Zhang J, Ney PA (2009). Role of BNIP3 and NIX in cell death, autophagy, and mitophagy. Cell Death Diff 16(939. doi: 10.1038/cdd.2009.16

184. Wu W, Tian W, Hu Z, Chen G, Huang L, Li W, Zhang X, Xue P, Zhou C, Liu L, Zhu Y, Zhang X, Li L, Zhang L, Sui S, Zhao B, Feng D (2014). ULK1 translocates to mitochondria and phosphorylates FUNDC1 to regulate mitophagy. EMBO Rep 15(5): 566-575. doi: 10.1002/embr.201438501

185. Zhang W, Siraj S, Zhang R, Chen Q (2017). Mitophagy receptor FUNDC1 regulates mitochondrial homeostasis and protects the heart from I/R injury. Autophagy 13(6): 1080-1081. doi: 10.1080/15548627.2017.1300224 
186. Allen GFG, Toth R, James J, Ganley IG (2013). Loss of iron triggers PINK1/Parkin-independent mitophagy. EMBO Rep 14(12): 1127-1135 doi: 10.1038/embor.2013.168

187. McWilliams TG, Prescott AR, Montava-Garriga L, Ball G, Singh F, Barini E, Muqit MMK, Brooks SP, Ganley IG (2018). Basal Mitophagy Occurs Independently of PINK1 in Mouse Tissues of High Metabolic Demand. Cell Metab 27(2): 439-449.e435. doi 10.1016/j.cmet.2017.12.008

188. Twig G, Shirihai OS (2011). The Interplay Between Mitochondrial Dynamics and Mitophagy. Antioxid Redox Signal 14(10): 1939-1951. doi: $10.1089 /$ ars.2010.3779

189. Pickles S, Vigié P, Youle RJ (2018). Mitophagy and Quality Control Mechanisms in Mitochondrial Maintenance. Curr Biol 28(4): R170 R185. doi: 10.1016/j.cub.2018.01.004

190. Mendl N, Occhipinti A, Müller M, Wild P, Dikic I, Reichert AS (2011). Mitophagy in yeast is independent of mitochondrial fission and requires the stress response gene WHI2. J Cell Sci 124(8): 13391350. doi: $10.1242 /$ jcs.076406

191. Yang L, Long Q, Liu J, Tang H, Li Y, Bao F, Qin D, Pei D, Liu X (2015). Mitochondrial fusion provides an 'initial metabolic complementation' controlled by mtDNA. Cell Mol Life Sci 72(13): 2585-2598. doi: 10.1007/s00018-015-1863-9

192. Romanello V, Sandri M (2015). Mitochondrial Quality Control and Muscle Mass Maintenance. Front Physiol 6: 422. doi: 10.3389/fphys.2015.00422

193. Chen H, Vermulst M, Wang YE, Chomyn A, Prolla TA, McCaffery $J M, C h a n$ DC (2010). Mitochondrial fusion is required for mtDNA stability in skeletal muscle and tolerance of mtDNA mutations. Cell 141(2): 280-289. doi: 10.1016/j.cell.2010.02.026

194. Cagalinec M, Safiulina D, Liiv M, Liiv J, Choubey V, Wareski P, Veksler V, Kaasik A (2013). Principles of the mitochondrial fusion and fission cycle in neurons. J Cell Sci 126(10): 2187 . doi: $10.1242 /$ jcs. 118844

195. Eisner V, Cupo RR, Gao E, Csordás G, Slovinsky WS, Paillard M, Cheng L, Ibetti J, Chen SRW, Chuprun JK, Hoek JB, Koch WJ, Hajnóczky $G$ (2017). Mitochondrial fusion dynamics is robust in the heart and depends on calcium oscillations and contractile activity. Proc Natl Acad Sci U S A 114(5): E859. doi: 10.1073/pnas.1617288114

196. Cavellini L, Meurisse J, Findinier J, Erpapazoglou Z, BelgarehTouzé N, Weissman AM, Cohen MM (2017). An ubiquitin-dependent balance between mitofusin turnover and fatty acids desaturation regulates mitochondrial fusion. Nat Commun 8: 15832. doi: 10.1038/ncomms15832

197. Mishra P, Carelli V, Manfredi G, Chan DC (2014). Proteolytic cleavage of Opa1 stimulates mitochondrial inner membrane fusion and couples fusion to oxidative phosphorylation. Cell Metab 19(4): 630-641. doi: 10.1016/j.cmet.2014.03.011

198. Szabo A, Sumegi K, Fekete K, Hocsak E, Debreceni B, Setalo G, Kovacs K, Deres L, Kengyel A, Kovacs D, Mandl J, Nyitrai M, Febbraio MA, Gallyas F, Sumegi B (2018). Activation of mitochondrial fusion provides a new treatment for mitochondria-related diseases. Biochem Pharmacol 150: 86-96. doi: 10.1016/j.bcp.2018.01.038

199. Miret-Casals L, Sebastián D, Brea J, Rico-Leo EM, Palacín M, Fernández-Salguero PM, Loza MI, Albericio F, Zorzano A (2018). Identification of New Activators of Mitochondrial Fusion Reveals a Link between Mitochondrial Morphology and Pyrimidine Metabolism. Cell Chem Biol 25(3): 268-278.e264. doi: 10.1016/j.chembiol.2017.12.001

200. Rocha AG, Franco A, Krezel AM, Rumsey JM, Alberti JM, Knight WC, Biris N, Zacharioudakis E, Janetka JW, Baloh RH, Kitsis RN, Mochly-Rosen D, Townsend RR, Gavathiotis E, Dorn GW (2018). MFN2 agonists reverse mitochondrial defects in preclinical models of Char-
cot-Marie-Tooth disease type 2A. Science 360(6386): 336. doi: 10.1126/science.aao1785

201. Ross FA, MacKintosh C, Hardie DG (2016). AMP-activated protein kinase: a cellular energy sensor that comes in 12 flavours. FEBS $J$ 283(16): 2987-3001. doi: 10.1111/febs.13698

202. Lin S-C, Hardie DG (2018). AMPK: Sensing Glucose as well as Cellular Energy Status. Cell Metab 27(2): 299-313. doi: 10.1016/j.cmet.2017.10.009

203. Cantó C, Jiang LQ, Deshmukh AS, Mataki C, Coste A, Lagouge $M$, Zierath JR, Auwerx J (2010). Interdependence of AMPK and SIRT1 for metabolic adaptation to fasting and exercise in skeletal muscle. Cell Metab 11(3): 213-219. doi: 10.1016/j.cmet.2010.02.006

204. Puigserver P, Wu Z, Park CW, Graves R, Wright M, Spiegelman BM (1998). A Cold-Inducible Coactivator of Nuclear Receptors Linked to Adaptive Thermogenesis. Cell 92(6): 829-839. doi: 10.1016/S00928674(00)81410-5

205. Puigserver $P$, Spiegelman BM (2003). Peroxisome ProliferatorActivated Receptor- $\gamma$ Coactivator $1 \alpha$ (PGC-1 $\alpha$ ): Transcriptional Coactivator and Metabolic Regulator. Endocr Rev 24(1): 78-90. doi: 10.1210/er.2002-0012

206. Leick L, Fentz J, Biens $\emptyset$ RS, Knudsen JG, Jeppesen J, Kiens B, Wojtaszewski JFP, Pilegaard H (2010). PGC-1 $\alpha$ is required for AICARinduced expression of GLUT4 and mitochondrial proteins in mouse skeletal muscle. Am J Physiol Endocrinol Metab 299(3): E456-E465. doi: 10.1152/ajpendo.00648.2009

207. Jäger S, Handschin C, St.-Pierre J, Spiegelman BM (2007). AMP activated protein kinase (AMPK) action in skeletal muscle via direct phosphorylation of PGC-1 $\alpha$. Proc Natl Acad Sci U S A 104(29): 12017 12022. doi: $10.1073 /$ pnas.0705070104

208. Terada S, Goto M, Kato M, Kawanaka K, Shimokawa T, Tabata I (2002). Effects of low-intensity prolonged exercise on PGC-1 mRNA expression in rat epitrochlearis muscle. Biochem Biophys Res Commun 296(2): 350-354. doi: 10.1016/S0006-291X(02)00881-1

209. Suwa M, Nakano $H$, Kumagai S (2003). Effects of chronic AICAR treatment on fiber composition, enzyme activity, UCP3, and PGC-1 in rat muscles. J Appl Physiol 95(3): 960-968. doi: 10.1152/japplphysiol.00349.2003

210. Cantó C, Gerhart-Hines Z, Feige JN, Lagouge M, Noriega L, Milne JC, Elliott PJ, Puigserver P, Auwerx J (2009). AMPK regulates energy expenditure by modulating $\mathrm{NAD}(+)$ metabolism and SIRT1 activity. Nature 458(7241): 1056-1060. doi: 10.1038/nature07813

211. Narkar VA, Downes $M, Y u$ RT, Embler E, Wang Y-X, Banayo $E$, Mihaylova MM, Nelson MC, Zou $Y$, Juguilon $H$, Kang $H$, Shaw R, Evans RM (2008). AMPK and PPAR $\delta$ agonists are exercise mimetics. Cell 134(3): 405-415. doi: 10.1016/j.cell.2008.06.051

212. Fulco $M$, Cen $Y$, Zhao $P$, Hoffman EP, McBurney MW, Sauve AA Sartorelli $V$ (2008). Glucose Restriction Inhibits Skeletal Myoblast Differentiation by Activating SIRT1 through AMPK-Mediated Regulation of Nampt. Dev Cell 14(5): 661-673. doi: 10.1016/j.devcel.2008.02.004

213. Cantó C, Auwerx J (2012). Targeting SIRT1 to improve metabolism: all you need is $N A D(+)$ ? Pharmacol Rev 64(1): 166-187. doi: $10.1124 /$ pr.110.003905

214. Rodgers JT, Lerin C, Haas W, Gygi SP, Spiegelman BM, Puigserver $P$ (2005). Nutrient control of glucose homeostasis through a complex of PGC-1 $\alpha$ and SIRT1. Nature 434(7029): 113. doi: 10.1038/nature03354

215. Scarpulla RC, Vega RB, Kelly DP (2012). Transcriptional integration of mitochondrial biogenesis. Trends Endocrinol Metab 23(9): 459-466. doi: 10.1016/j.tem.2012.06.006 
216. Luo C, Widlund HR, Puigserver P (2016). PGC-1 Coactivators: Shepherding the Mitochondrial Biogenesis of Tumors. Trends Cancer 2(10): 619-631. doi: 10.1016/j.trecan.2016.09.006

217. Mouchiroud L, Houtkooper RH, Moullan N, Katsyuba E, Ryu D, Cantó C, Mottis A, Jo Y-S, Viswanathan M, Schoonjans K, Guarente L, Auwerx J (2013). The $N A D(+) /$ sirtuin pathway modulates longevity through activation of mitochondrial UPR and FOXO signaling. Cell 154(2): 430-441. doi: 10.1016/j.cell.2013.06.016

218. Gospodarska E, Nowialis P, Kozak LP (2015). Mitochondrial turnover: a phenotype distinguishing brown adipocytes from interscapular brown adipose tissue and white adipose tissue. J Biol Chem 290(13): 8243-8255. doi: 10.1074/jbc.M115.637785
219. Plotegher N, Duchen MR (2017). Mitochondrial Dysfunction and Neurodegeneration in Lysosomal Storage Disorders. Trends Mol Med 23(2): 116-134. doi: 10.1016/j.molmed.2016.12.003

220. Benador IY, Veliova M, Mahdaviani K, Petcherski A, Wikstrom JD, Assali EA, Acín-Pérez R, Shum M, Oliveira MF, Cinti S, Sztalryd C, Barshop WD, Wohlschlegel JA, Corkey BE, Liesa M, Shirihai OS (2018). Mitochondria Bound to Lipid Droplets Have Unique Bioenergetics, Composition, and Dynamics that Support Lipid Droplet Expansion. Cell Metab 27(4): 869-885.e866. doi: 10.1016/j.cmet.2018.03.003 